\title{
Influence of Rigid Segment Type on Copoly(ether-ester) Properties
}

\author{
Konrad Walkowiak ${ }^{1}$, Izabela Irska ${ }^{1}$ (), Agata Zubkiewicz ${ }^{2}$, Zbigniew Rozwadowski ${ }^{3}$ (D) \\ and Sandra Paszkiewicz ${ }^{1, *(\mathbb{D})}$ \\ 1 Department of Materials Technologies, West Pomeranian University of Technology, Al. Piastów 19, \\ 70-310 Szczecin, Poland; wk42388@zut.edu.pl (K.W.); izabela.irska@zut.edu.pl (I.I.) \\ 2 Department of Physics, West Pomeranian University of Technology, Al. Piastów 48, 70-311 Szczecin, Poland; \\ agata.zubkiewicz@zut.edu.pl \\ 3 Department of Inorganic and Analytical Chemistry, West Pomeranian University of Technology, \\ Al. Piastów 42, 71-065 Szczecin, Poland; zbigniew.rozwadowski@zut.edu.pl \\ * Correspondence: sandra.paszkiewicz@zut.edu.pl; Tel.: +48-91-449-45-89
}

Citation: Walkowiak, K.; Irska, I.; Zubkiewicz, A.; Rozwadowski, Z.; Paszkiewicz, S. Influence of Rigid Segment Type on Copoly(ether-ester) Properties. Materials 2021, 14, 4614. https://doi.org/10.3390/ma14164614

Academic Editors: Alfonso Maffezzoli and Rafał Malinowski

Received: 27 July 2021

Accepted: 14 August 2021

Published: 17 August 2021

Publisher's Note: MDPI stays neutral with regard to jurisdictional claims in published maps and institutional affiliations.

Copyright: (C) 2021 by the authors. Licensee MDPI, Basel, Switzerland. This article is an open access article distributed under the terms and conditions of the Creative Commons Attribution (CC BY) license (https:/ / creativecommons.org/licenses/by/ $4.0 /)$.

\begin{abstract}
The growing ecological awareness of society created the tendency to replace petrochemically based materials with alternative energy carriers and renewable raw materials. One of the most requested groups of polymer materials with significant technological importance is thermoplastic elastomers (TPE). They combine the properties of elastomers such as flexibility with the typical properties of thermoplastics, like easy processing. Herein, one compares the influence of rigid segments on the properties of copoly(ester-ether). Thermoplastic polyesters based on bio-1,6-hexanediol and terephthalic (T), furanic $(\mathrm{F})$, and napthalate $(\mathrm{N})$ diesters, i.e., PHT, PHF, and PHN, were obtained employing melt polycondensation. Additionally, to grant elastic properties of polyesters, systems containing 50 wt.\% of bio-based polyTHF ${ }^{\circledR} 1000$ (pTHF) with a molecular mass of $1000 \mathrm{~g} / \mathrm{mol}$, have been prepared. The composition and chemical structure have been determined by ${ }^{1} \mathrm{H}$ nuclear magnetic resonance (NMR) and Fourier transformed infrared spectroscopy (FTIR) analyses. The temperatures corresponding to phase transition changes were characterized by differential scanning calorimetry (DSC) and dynamic mechanical thermal analysis (DMTA) analyses. The crystalline structure was examined by X-ray diffraction (XRD) analysis. Additionally, the influence of pTHF-rich segment on the tensile properties, water absorption, as well as thermal and thermo-oxidative stability, has been analyzed. It was found that incorporation of soft phase allows creation of thermoplastic elastomers with tensile characteristics comparable to the commercially available ones, by means of elongation at break higher than $500 \%$, low values of tensile modulus, without exhibiting yield point.
\end{abstract}

Keywords: polymer synthesis; polycondensation in melt; polymer modification; 1,6-hexanodiol; dimethyl 2,5-furandicarboxyle; dimethyl terephthalate; dimethyl napthalate; copolymers; biopolymers; polymer characteristics

\section{Introduction}

The increasing awareness in the field of ecology within our society has led to the necessity of creating demand for replacing chemical products made from petroleum with renewable raw materials. Therefore, there is a growing interest in materials like poly(tetrahydrofuran) (polyTHF). PolyTHF is a bio-based derivative from 1,4-butanediol [1]. This material possesses characteristic high chain flexibility, and because of that it has a low melting point between $-15^{\circ} \mathrm{C}$ to $30^{\circ} \mathrm{C}$, which depends on its molecular weight. The bio-based PolyTHF ${ }^{\circledR} 1000$ produced by BASF has identical properties to a petrochemicalbased product [1]. PolyTHF can be used in the production of spandex fibers or artificial leather [2]. Furthermore, it can be used for the synthesis of thermoplastic polyurethane [1,2]. Another material worthy of notice is 1,6-hexanediol (1,6-HDO) produced by Rennovia Inc. Bio-based 1,6-HDO is synthesized from glucose. 1,6-HDO finds applications in the production of coatings, adhesives, and elastomers [3]. 
Furandicarboxylic acid (FDCA) is one of the most important renewable materials, and it is recognized as one of the most important building-block chemicals by the US Department of energy [4,5]. Thanks to its chemical structure, FDCA is considered an alternative to terephthalic acid (TPA) [4-8]. Therefore, FDCA or its derivatives like dimethyl 2,5-furanodicarboxylate (DMFDC) find use in the synthesis of polyesters [9]. Studies show that poly(ethylene 2,5-furanodicarboxylate) has a higher tensile modulus and barrier performance than PET [4,9]. Thus, PEF can be used in the production of films, bottles, and fibers.

Poly(hexamethylene terephthalate) (PHT) is non-commercial semicrystalline aromatic polyester $[8,10,11]$. Therefore, PHT has good mechanical properties and chemical resistance $[8,11]$. PHT is polymorphic polyester, which has three crystal structures: $\alpha, \beta$, and $\gamma$. The $\gamma$ is the rarest form because this crystal structure is converted to the other structures by annealing or orientation [12,13]. Replacement of TPA with FDCA, or its derivatives, results in achieving polyesters fully made from renewable materials. In that case poly(hexamethylene 2,5-furanodicarboxylate) (PHF) was synthesized by Moore and Kelly in 1978 [7]. PHF has lower thermal stability and glass transition temperature in comparison to PEF or PTF. The reason for that is the higher methylene number of aliphatic diols in PHF [14]. Same as PHT, PHF is non-commercial material. Polyesters based on 2,6-naphthalene dicarboxylic acid or its derivatives exhibit better or similar properties if compared to polyesters based on TPA. For example poly(ethylene naphthalate) (PEN) has better thermal, mechanical properties, and chemical resistance than PET [15]. The reason for the improvement is a double naphthalene ring in its structure [15]. Poly(hexamethylene naphthalate) (PHN), like PHT, is polymorphic polyester and exhibits two crystallite structures: $\alpha$ and $\beta[12,16]$. Similarly, PEN, PHN shows polymorphism induced by temperature and/or stress [17]. PHN investigated by Jeong et al. [16] has melting and glass temperature of 209 and $45{ }^{\circ} \mathrm{C}$, respectively. The crystallization rate of PHN is faster than PEN but slightly slower than that of poly(butylene naphthalate) (PBN) [16]. Thanks to its properties, $\mathrm{PHN}$ can be classified as an engineering thermoplastic [16].

The thermoplastic elastomers (TPEs) constitute a group of materials that combine the mechanical properties of elastomers and the processing properties of thermoplastics. Their properties result from morphology, which consists of rigid and flexible segments. A flexible segment forms a matrix in which rigid-segment domains are immersed [18]. Unlike elastomers, the rigid-segment domains of TPE form physical crosslinking [18]. TPE produced by polycondensation or polyaddition can be classified into three groups: polyester-based, polyamide-based, and polyurethane-based [19]. Poly(ether-ester) (PEE) block copolymers are polyester-based TPE, that were commercialized, especially those based on poly(butylene terephthalate) (PBT) as rigid-segment and poly(tetramethylene oxide) (PTMO), also called poly(tetrahydrofuran) (polyTHF) as flexible segment. The most popular commercial representative of these materials is Hytrel ${ }^{\circledR}$ (DuPont) [20]. TPEs are widely used in many commercial applications, like for the production of bottles, films, caps, etc. TPEs also find applications in medical, surgical, and pharmaceutical activities [19]. However, TPEs are most widely used in the automotive industry, in the production of mounting elements, vibration control elements, floor mats, cup holders, and cable sleeves [19].

This study aims to analyze the influence of rigid segment type on the properties of copoly(ether-ester)s. The PHF, PHT, PHN, and copoly(ether-ester)s by means of PHF-bF-pTHF 50/50, PHT-b-T-pTHF 50/50, and PHN-b-N-pTHF 50/50 were synthesized via melt polycondensation. The composition and chemical structure were determined by ${ }^{1} \mathrm{H}$ nuclear magnetic resonance (NMR) and Fourier transform infrared spectroscopy (FTIR). The temperatures corresponding to phase transition changes were investigated by differential scanning calorimetry (DSC) and dynamic mechanical thermal analysis (DMTA). The crystalline structure of the synthesized materials has been evaluated by X-ray diffraction (XRD). The influence of flexible segment on static tensile properties, intrinsic viscosity, and water absorption was evaluated. Besides, thermal and thermo-oxidative stability has 
been analyzed, to evaluate the utilitarian properties of the synthesized polyesters and copoly(ether-esters).

\section{Materials and Methods}

\subsection{Synthesis of PHF, PHT, PHN, and Copoly(ether-ester)s Based on Them}

Synthesized polyesters and PEE were obtained from dimethyl terephthalate (DMT, SigmaAldrich, Germany), dimethyl naphthalene (DMN, Sigma-Aldrich, Germany), dimethyl 2,5-furanodicarboxylate (DMFDC, 99\%, Henan Coreychem Co., Ltd., Zhengzhou, China), 1,6-hexylene glycol (HDO, Rennovia Inc., Santa Clara, CA, USA), and poly(tetrahydrofuran) (pTHF, BASF, Ludwigshafen, Germany) with a molecular mass of $1000 \mathrm{~g} / \mathrm{mol}$. Materials were synthesized in two steps (Figure 1). In the first step, transesterification of diester (DMFDC/DMT/DMN) by HDO with the presence of the first portion of catalyst (tetrabuthyl orthotitanate, $\mathrm{Ti}(\mathrm{OBu})_{4}$, (Fluka)) was carried out. Secondly, the polycondensation stage was performed in the presence of the second portion of catalyst (also $\left.\mathrm{Ti}(\mathrm{Obu})_{4}\right)$ along with the thermal stabilizer, Irganox 1010 (Ciba-Geigy, Basel, Switzerland). Additionally, during polycondensation of copoly(ether-ester)s pTHF was added. The synthesis was performed in a $1 \mathrm{dm}^{3}$ high-pressure reactor (Autoclave Engineers, Erie, PA, USA). The reactor is equipped with a condenser, cold trap for collecting the by-product, and vacuum pump. During the transesterification, the reactor was loaded with DMFDC/DMT/DMN, HDO, and catalyst. The molar ratio of the diester (DMFDC/DMT/DMN) and glycol (HDO) was 1:1.5. The first step of reaction was performed in the presence of a constant flow of nitrogen at the temperature and time that can be found in Table 1. During the transesterification, methanol was distilled and collected as the first by-product. The end of the first step was signalized by the amount of effluent by-product. When $90 \%$ of the stoichiometric amount of methanol was ceased, the process was completed. Subsequently, one increased the temperature up to $210^{\circ} \mathrm{C}$ and added a catalyst and thermal stabilizer to the reactor. Additionally, if it was the synthesis of copoly(ether-ester)s, pTHF was added to the reactor. The reaction temperature was increased to a value of the end temperature of the polycondensation (Table 1). A vacuum was applied to remove HDO excess and lower the final pressure to $25 \mathrm{~Pa}$. The progress of polycondensation was monitored by observation of stirring torque change, which was used to evaluate the melt viscosity of the product. The end of the polycondensation process was signalized by the proper value of melt viscosity of the reaction mixture that was adequate to the value of melt viscosity of a high molecular mass of the polymer material. After the polycondensation process, the material was extruded from the reactor into the water bath with the use of compressed nitrogen. All synthesized copoly(ether-ester)s were named as follows: rigid segment-b-diester unit-flexible segment, since for the flexible segment one diester unit $(\mathrm{F} / \mathrm{T} / \mathrm{N})$ is included with pTHF sequence, e.g., PHF-b-F-pTHF. In the same manner, all of the other copoly(ether-esters) based on diester of terephthalate $(\mathrm{T})$ and naphthalene $(\mathrm{N})$ acids were designated. 


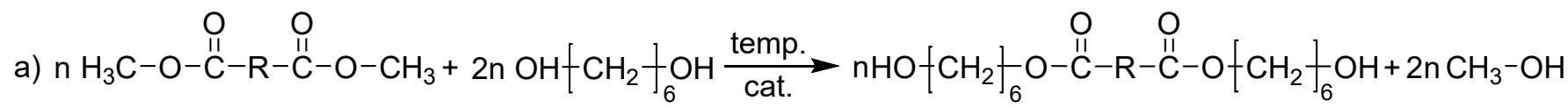

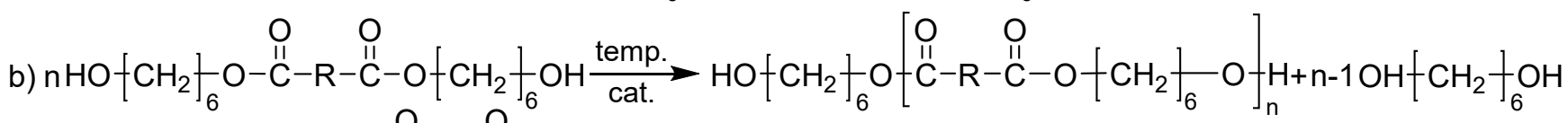
c) $\mathrm{nHO}+\mathrm{CH}_{2} f_{6} \mathrm{O}-\stackrel{\mathrm{O}}{\mathrm{C}}-\mathrm{R}-\stackrel{\mathrm{II}}{\mathrm{C}}-\mathrm{O}+\mathrm{CH}_{2} \mathrm{f}_{6} \mathrm{OH}+\mathrm{HO}+\mathrm{CH}_{2} \cdot \mathrm{CH}_{2} \cdot \mathrm{CH}_{2} \cdot \mathrm{CH}_{2} \cdot \mathrm{O} \mathrm{f}_{\mathrm{n}} \mathrm{OH} \frac{\text { temp. }}{\text { cat. }}$

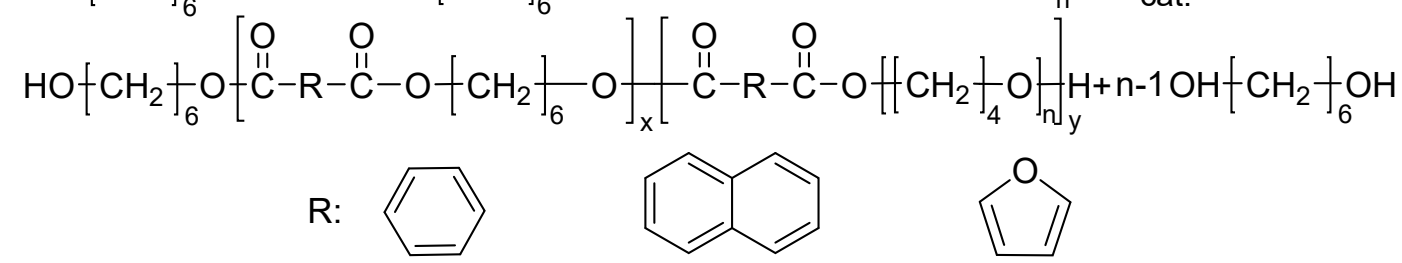

Figure 1. Synthesis reaction of (a) transesterification of polyesters and copoly(ether-ester)s; (b) polycondensation of polyesters; (c) polycondensation of copoly(ether-ester)s.

Table 1. Temperatures and times used in the synthesis of polyesters and copoly(ether-ester)s.

\begin{tabular}{|c|c|c|c|c|c|}
\hline \multirow{2}{*}{ Sample } & \multicolumn{3}{|c|}{ Transesterification } & \multicolumn{2}{|c|}{ Polycondensation } \\
\hline & $\mathrm{T}_{\mathrm{p}}\left({ }^{\circ} \mathrm{C}\right)$ & $\mathrm{T}_{\mathrm{kT}}\left({ }^{\circ} \mathrm{C}\right)$ & Time (min) & $\mathrm{T}_{\mathrm{kP}}\left({ }^{\circ} \mathrm{C}\right)$ & Time (min) \\
\hline PHF & 165 & 185 & 70 & 235 & 370 \\
\hline PHF-b-F-pTHF 50/50 & 165 & 185 & 96 & 235 & 344 \\
\hline PHT & 175 & 185 & 85 & 255 & 350 \\
\hline $\begin{array}{c}\text { PHT-b-T-pTHF } \\
50 / 50\end{array}$ & 175 & 185 & 93 & 250 & 423 \\
\hline PHN & 175 & 195 & 125 & 255 & 285 \\
\hline $\begin{array}{c}\text { PHN-b-N-pTHF } \\
50 / 50\end{array}$ & 175 & 190 & 125 & 250 & 388 \\
\hline
\end{tabular}

$\mathrm{T}_{\mathrm{p}}$-starting temperature of transesterification; $\mathrm{T}_{\mathrm{kT}}$ —ending temperature of transesterification; $\mathrm{T}_{\mathrm{kP}}$-ending temperature of polycondensation.

Subsequently, the extruded materials were pelletized on the laboratory mill. Then materials were injection molded using Boy 15 (Dr Boy GmbH\&Co., Neutstadt, Germany) for a dumbbell shape sample, type A3, that was being used for DMTA, water absorption, and tensile measurements. Before injection molding, pellets were dried for $24 \mathrm{~h}$ under a vacuum at the temperature of $55^{\circ} \mathrm{C}$. The parameters of injection can be found in Table 2.

Table 2. Injection molding parameters of polyesters and copoly(ether-ester)s.

\begin{tabular}{ccccccc}
\hline Sample & $\mathbf{T}_{\mathbf{f}}\left({ }^{\circ} \mathbf{C}\right)$ & $\mathbf{T}_{\mathbf{i}}\left({ }^{\circ} \mathbf{C}\right)$ & $\left.\mathbf{P}_{\mathbf{d}} \mathbf{( M P a}\right)$ & $\left.\mathbf{P}_{\mathbf{i}} \mathbf{( M P a}\right)$ & $\mathbf{t}_{\mathbf{i}}(\mathbf{s})$ & 7 \\
\hline PHF & 30 & 180 & 20 & 55 & 7 & 7 \\
PHF-b-F-pTHF 50/50 & 30 & 170 & 8 & 45 & 5 & 25 \\
PHT & 30 & 190 & 30 & 70 & 6 & 20 \\
PHT-b-T-pTHF 50/50 & 30 & 150 & 12 & 50 & 5 & 5 \\
PHN & 30 & 230 & 25 & 50 & 5 & 5 \\
PHN-b-N-pTHF 50/50 & 30 & 210 & 25 & 50 & 5 \\
\hline
\end{tabular}

$\mathrm{T}_{\mathrm{f}}$-temperature of form; $\mathrm{T}_{\mathrm{i}}$-temperature of injection; $\mathrm{P}_{\mathrm{d}}$-holding down pressure; $\mathrm{P}_{\mathrm{i}}$-injection pressure; $\mathrm{t}_{\mathrm{i}}$ - time of injection; $\mathrm{t}_{\mathrm{c}}$-time of cooling.

\subsection{Characterization Methods}

The chemical structure and composition of the synthesized materials were investigated by ${ }^{1} \mathrm{H}$ NMR spectroscopy. Before the experiment, samples were subjected to esterification. ${ }^{1} \mathrm{H}$ NMR spectroscopy was carried out on Bruker spectrometer operating at a frequency of $400 \mathrm{MHz}$ (Bruker, Karlsruhe, Germany). The chloroform-d CDCl3 at 
a concentration of $10 \mathrm{mg} / \mathrm{mL}$ was used to dissolve samples. For internal chemical shift reference, tetramethylsilane (TMS) was used.

The polyesters and copoly(ether-ester)s were characterized using an FTIR spectrophotometer Nicolet iS 5 FTIR Spectrometer (Thermo Fisher Scientific Inc., Waltham, MA, USA). Samples were tested with the attenuated total reflectance (ATR) technique. Each sample was scanned 17 times over the frequency range of $4000-400 \mathrm{~cm}^{-1}$.

The intrinsic viscosity (IV) of synthesized polyesters and copoly(ether-ester)s was investigated at $30^{\circ} \mathrm{C}$ in the mixture of phenol/1,1,2,2- tetrachloroethane ( $60 / 40$ by weight). The concentration of polymer solution was $0.5 \mathrm{~g} / \mathrm{dl}$. The intrinsic viscosity was characterized using a capillary Ubbehlode viscometer (type Ic, $\mathrm{K}=0.03294$ ).

Density was studied by hydrostatic weighing method with the use of AGN200C (Axis LLC, Gdańsk, Poland).

Additionally, water absorption tests were performed in cold and boiling water. The measurement was carried out according to the procedures recommended in ASTM D570. Firstly, the dumbbell shape samples were dried at $55^{\circ} \mathrm{C}$ for $24 \mathrm{~h}$. Subsequently, samples were cooled to room temperature and weighted. The measurement of water absorption in boiling water was carried out for $30 \mathrm{~min}$, after that samples were cooled in distilled water for $15 \mathrm{~min}$. The water absorption in cold water was investigated by immersing samples in distilled water at $23^{\circ} \mathrm{C}$ for $24 \mathrm{~h}$. The water on the surface of the samples was removed with filled paper. After that, samples were weighted. Each reported value is an average of 3 test specimens.

Differential Scanning Calorimetry (DSC) measurement was performed using F1 Phoenix (Netzsch, Selb, Germany). The measurements were carried out over a temperature range of $-50{ }^{\circ} \mathrm{C}$ to $300{ }^{\circ} \mathrm{C}$ and again cooled to $-50{ }^{\circ} \mathrm{C}$ with a speed of $10^{\circ} \mathrm{C} / \mathrm{min}$ for polyesters. Copoly(ether-ester)s were investigated in the temperature range of $-90^{\circ} \mathrm{C}$ to $300{ }^{\circ} \mathrm{C}$ and again cooled to $-90^{\circ} \mathrm{C}$ with the same speed as polyesters. Additionally, only PHT and PHT-b-T-pTHF were heated to $250^{\circ} \mathrm{C}$. First heating was used only for deleting the thermal memory of the samples. In addition, in order to compare the DSC results with dynamic mechanical thermal analysis (DMTA) results, by means of phase transition temperatures, the DSC measurement was also carried out with the heating/cooling rates of $3{ }^{\circ} \mathrm{C} / \mathrm{min}$ in the temperature ranges adequate for polyesters and copoly(ether-esters), as above. The melting and crystallization temperatures $\left(\mathrm{T}_{\mathrm{m}}, \mathrm{T}_{\mathrm{c}}\right)$ were measured at the maximum of endo- and exothermic peaks, respectively. The glass transition temperature $\left(T_{g}\right)$ was taken as the midpoint of the change of the heat capacity $\left(\Delta C_{p}\right)$.

The X-ray diffraction (XRD) patterns of the catalysts were recorded with Empyrean (Malvern Panalytical, Malvern, UK) using $\operatorname{CuK}(\lambda=0.154 \mathrm{~nm})$ as the radiation source. The samples were scanned in a $2 \theta$ angle range of $10-35^{\circ}$ (with a step size of 0.05 ).

The dynamic mechanical thermal analysis (DMTA) was obtained using a DMA Q800 (TA Instruments, New Castle, DE, USA) working in a temperature range from $-100{ }^{\circ} \mathrm{C}$ to the polymer melt temperature, at a frequency of $1 \mathrm{~Hz}$ and a heating rate of $3^{\circ} \mathrm{C} / \mathrm{min}$. The properties were determined based on modulus changes and the ability of attenuation as a function of temperature and frequency of load changes.

The thermal and thermo-oxidative stability of materials were characterized using TGA92-16.18 (Setaram, Caluire-et-Cuire, France). The thermal stability was investigated in the atmosphere of argon when thermo-oxidative in the atmosphere of dry, synthetic air $\left(\mathrm{N}_{2}: \mathrm{O}_{2}=80: 20 \% \mathrm{vol}\right)$ with a flux rate of $20 \mathrm{~mL} / \mathrm{min}$. The study was carried out in the temperature range of $50-700{ }^{\circ} \mathrm{C}$ at a heating rate of $10^{\circ} \mathrm{C}$. The static mechanical properties were investigated using Autograph AG-X plus (Shimadzu, Kyoto, Japan). This machine is equipped with an optical extensometer, $1 \mathrm{kN}$ Shimadzu load cell, the TRAPEZIUM $\mathrm{X}$ software. Polyesters and copoly(ether-ester)s at the beginning were extended to $1 \%$ with a crosshead speed of $1 \mathrm{~mm} / \mathrm{min}$. Then, the stress-strain curves for polyesters were obtained at a rate of $5 \mathrm{~mm} / \mathrm{min}$. However, the stress-strain curves for copoly(ether-ester)s were obtained at a rate of $100 \mathrm{~mm} / \mathrm{min}$. Each reported value is an average of five test specimens. The measurements were performed according to PN-EN ISO 527. Finally, the 
hardness of polyesters and copoly(ether-ester)s was investigated using a Zwick 3100 Shore D tester (Zwick GmbH, Ulm, Germany). The reported values are the mean values of twenty independent measurements.

\section{Results}

\subsection{Chemical Structure, Composition, and Basic Physico-Chemical Properties}

Polyesters (PHF, PHT, PHN) and copoly(ether-ester)s based on these polyesters were synthesized by melt polycondensation which was described in the experimental session.

The theoretical chemical composition and the chemical composition estimated from ${ }^{1} \mathrm{H}$ NMR analysis are summarized in Table 3 . The NMR spectra of polyesters shown in Figure 2 differ from each other. For PHF, two furanoate ring protons appear as a singlet signal at $7.20 \mathrm{ppm}$ (d signal) [7]. The peak at $8.07 \mathrm{ppm}$ (e signal) is assigned to the protons of the terephthalate ring. Signals at $8.59,8.07$, and $7.98 \mathrm{ppm}\left(\mathrm{f}, \mathrm{g}\right.$, $\mathrm{h}$ signals) on the ${ }^{1} \mathrm{H}$ NMR spectra of PHN can be ascribed to protons of naphthalene ring [21]. The signals originating from methylene protons of hexylene glycol units appear at 1.45, 1.77, and $4.33 \mathrm{ppm}$ for PHF [22]. However, signals of methylene protons of hexylene glycol units slightly differ for other polyesters (PHT, PHN). They can be found at higher values due to the impact of the aromatic ring on a magnetic field.

Table 3. Calculated composition and basic physico-chemical properties of synthesized polymers.

\begin{tabular}{ccccccc}
\hline Material & $\mathbf{M}_{\mathbf{R}}$ & $\mathbf{M}_{\mathbf{F}}$ & $\mathbf{W}_{\mathbf{R}}$ & $\mathbf{W}_{\mathbf{F}}$ & {$[\mathbf{\eta}] \mathbf{( d \mathbf { l } / \mathbf { g } )}$} & $\mathbf{d} \mathbf{( g / \mathbf { c m } ^ { 3 } )}$ \\
\hline PHF & - & - & - & - & 0.825 & 1.260 \\
PHF-b-F-pTHF 50/50 & 238.24 & 210 & 47.51 & 52.49 & 1.350 & 1.137 \\
PHT & - & - & - & - & 0.952 & 1.235 \\
PHT-b-T-pTHF 50/50 & 248.28 & 220.22 & 47.09 & 52.91 & 1.026 & 1.132 \\
PHN & - & - & - & - & 0.626 & 1.247 \\
PHN-b-N-pTHF 50/50 & 298.34 & 270.29 & 43.62 & 56.38 & 1.176 \\
\hline
\end{tabular}

$\mathrm{M}_{\mathrm{R}}-$ molecular mass of rigid segment; $\mathrm{M}_{\mathrm{F}}-$ molecular mass of flexible segment; $\mathrm{W}_{\mathrm{R}}$-calculated content of rigid segment; $\mathrm{W}_{\mathrm{F}}-$ calculated content of rigid segment; [n]—intrinsic viscosity; d-density.
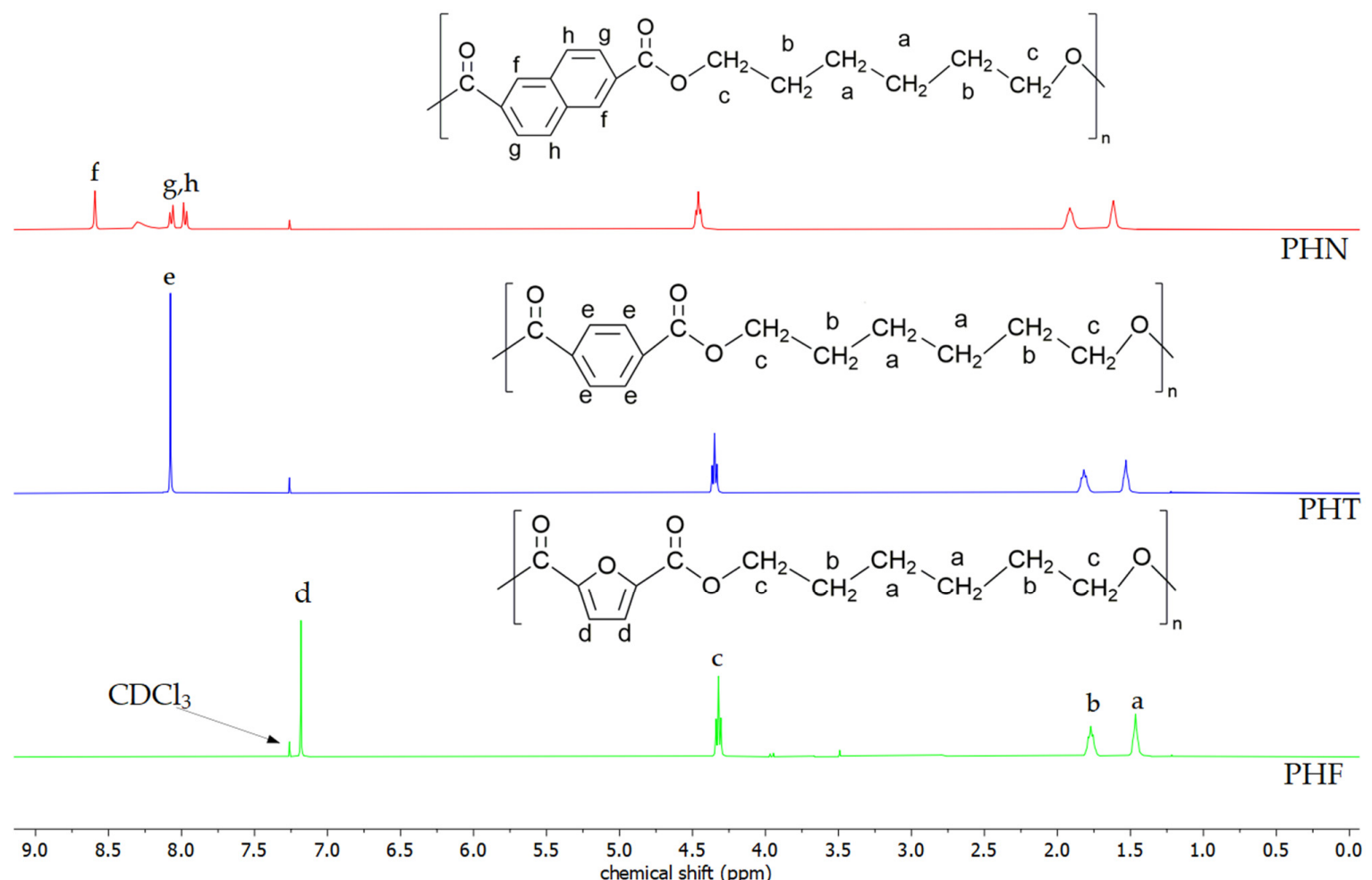

Figure 2. Structure of polyesters and their NMR spectra. 
Figures $3-5$ show a comparison of ${ }^{1} \mathrm{H}$ NMR spectra of polyesters and block copolymers. The ${ }^{1} \mathrm{H}$ NMR spectra of poly(ether-ester)s have four new resonance signals assigned to the protons of pTHF. Signal $i$ is assigned to inner methylene protons of pTHF ether block at $1.6 \mathrm{ppm}$ and outer methylene protons of ether block (signal $\mathrm{k}$ ) that can be found at $3.42 \mathrm{ppm}[22,23]$. The last two new signals are caused by a transesterification reaction between polyesters and pTHF what leads to a change in resonance of methylene group proton in pTHF. This effect is visible at 4.37 and $1.64-1.73 \mathrm{ppm}$ (signal $l$ and $j$, respectively). Moreover, due to the impact of the naphthalene ring on magnetic field peaks ascribed to signals a, i, and c, 1 have merged. Signal $\mathrm{m}$ is visible in ${ }^{1} \mathrm{H}$ NMR spectra of PHN-b-N-pTHF $50 / 50$ at $3.47-3.52 \mathrm{ppm}$ and is ascribed to protons from the ending group of macromolecule $-\mathrm{CH}_{2}-\mathrm{OH}$ [24].

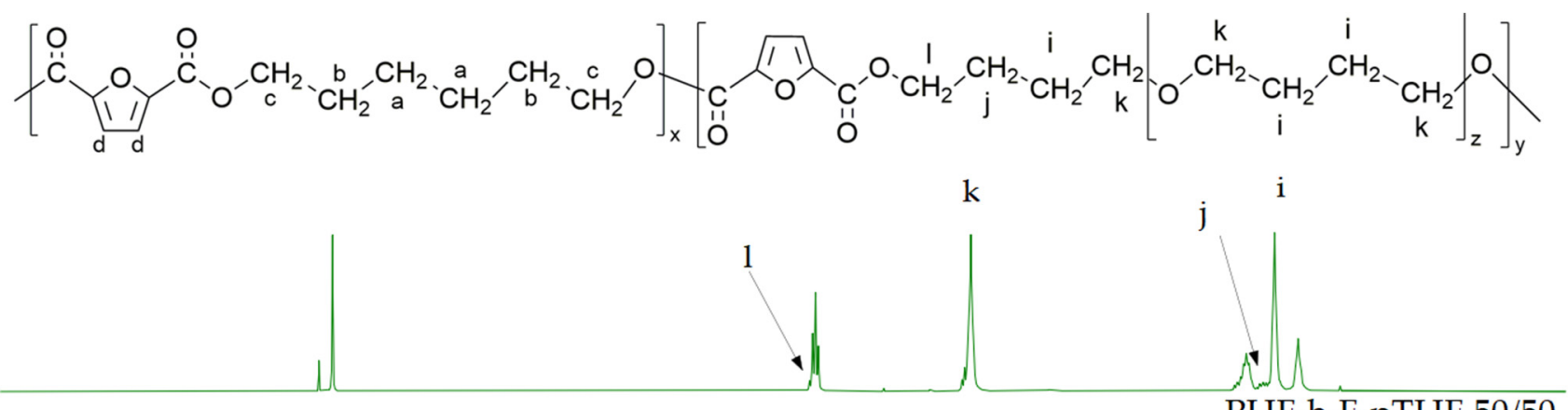

PHF-b-F-pTHF 50/50

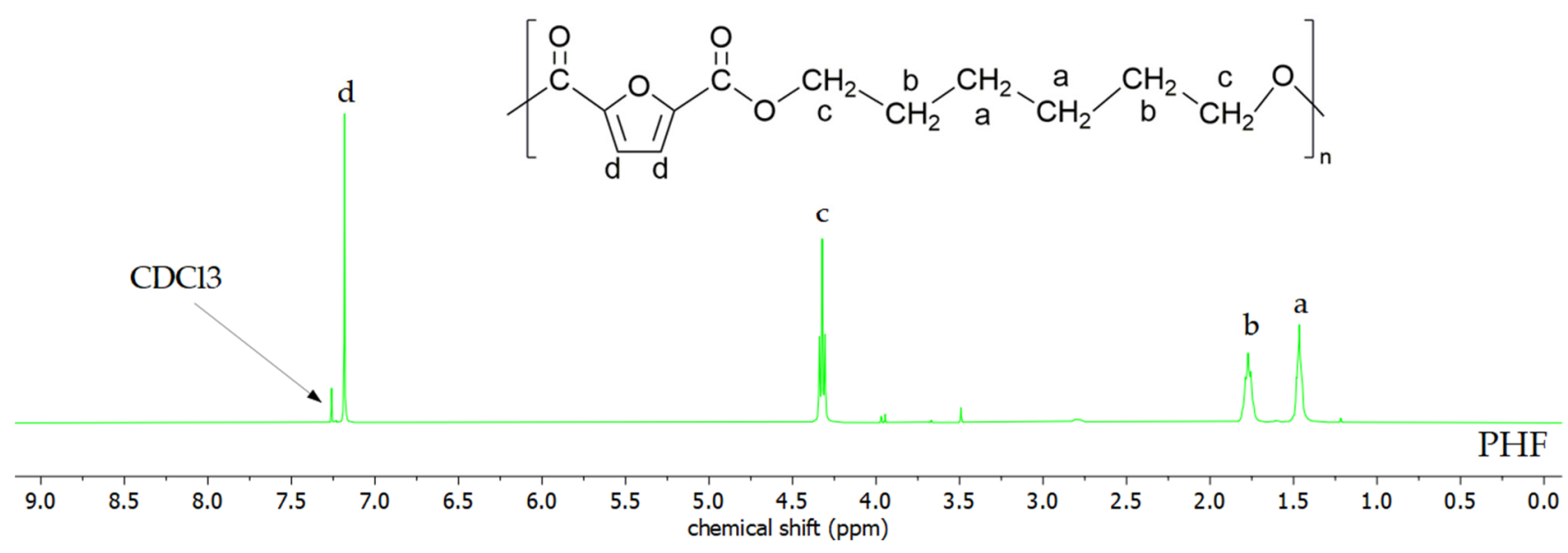

Figure 3. Structure and NMR spectra of PHF and PHF-b-F-pTHF 50/50. 


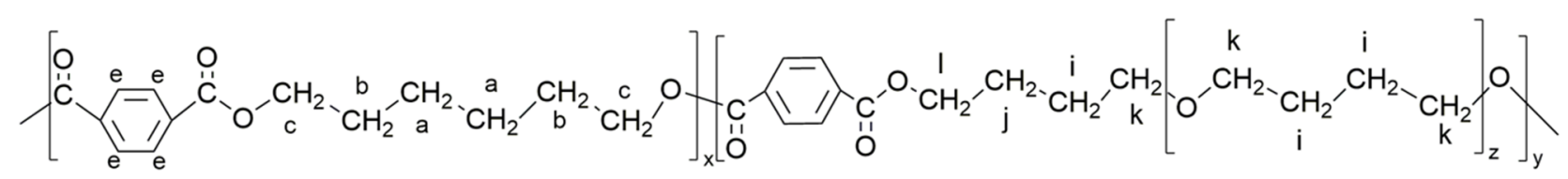

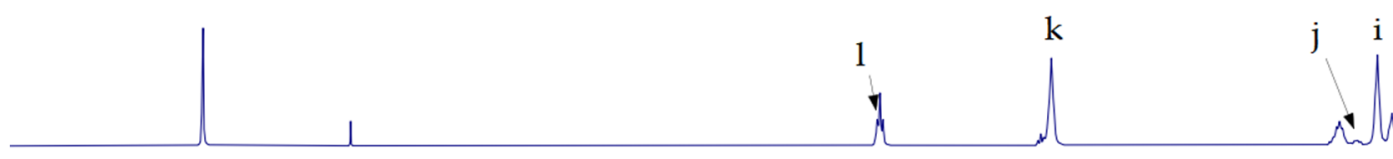

PHT-b-T-pTHF 50/50

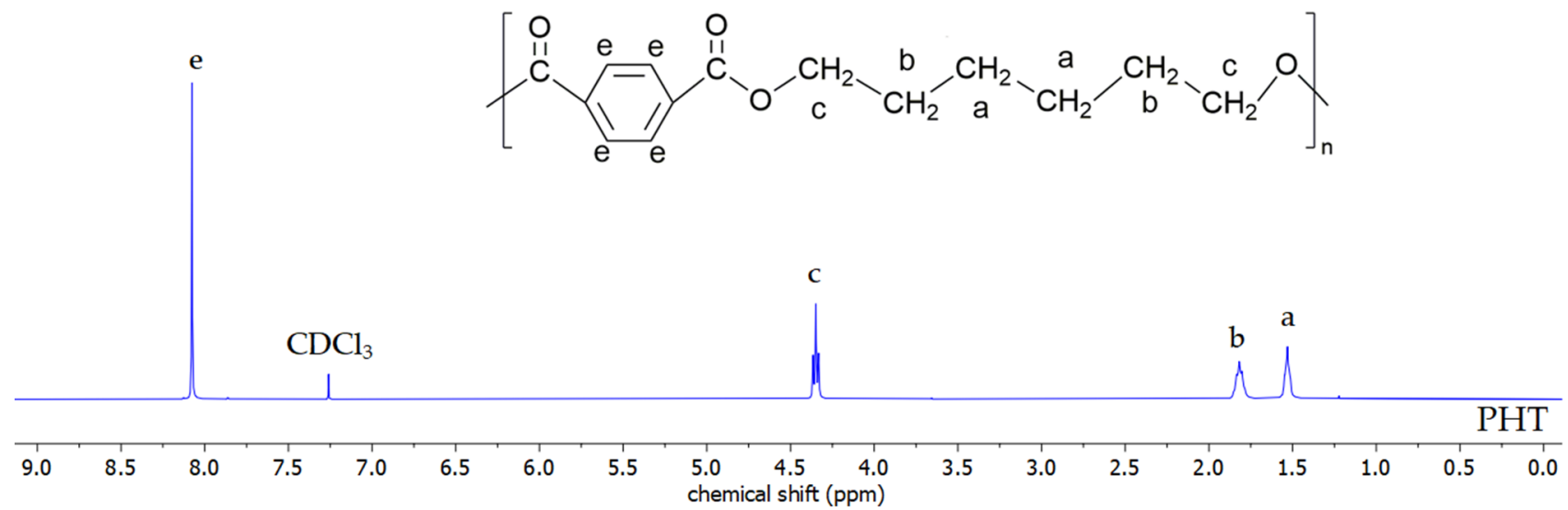

Figure 4. Structure and NMR spectra of PHT and PHT-b-T-pTHF 50/50.

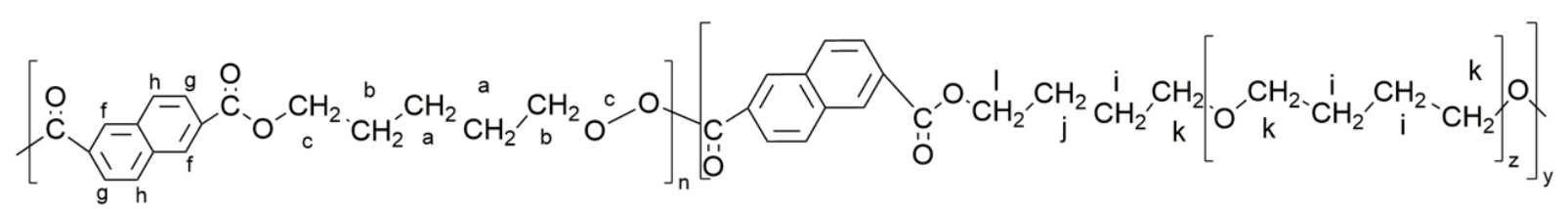

$\mathrm{a}, \mathrm{i}$

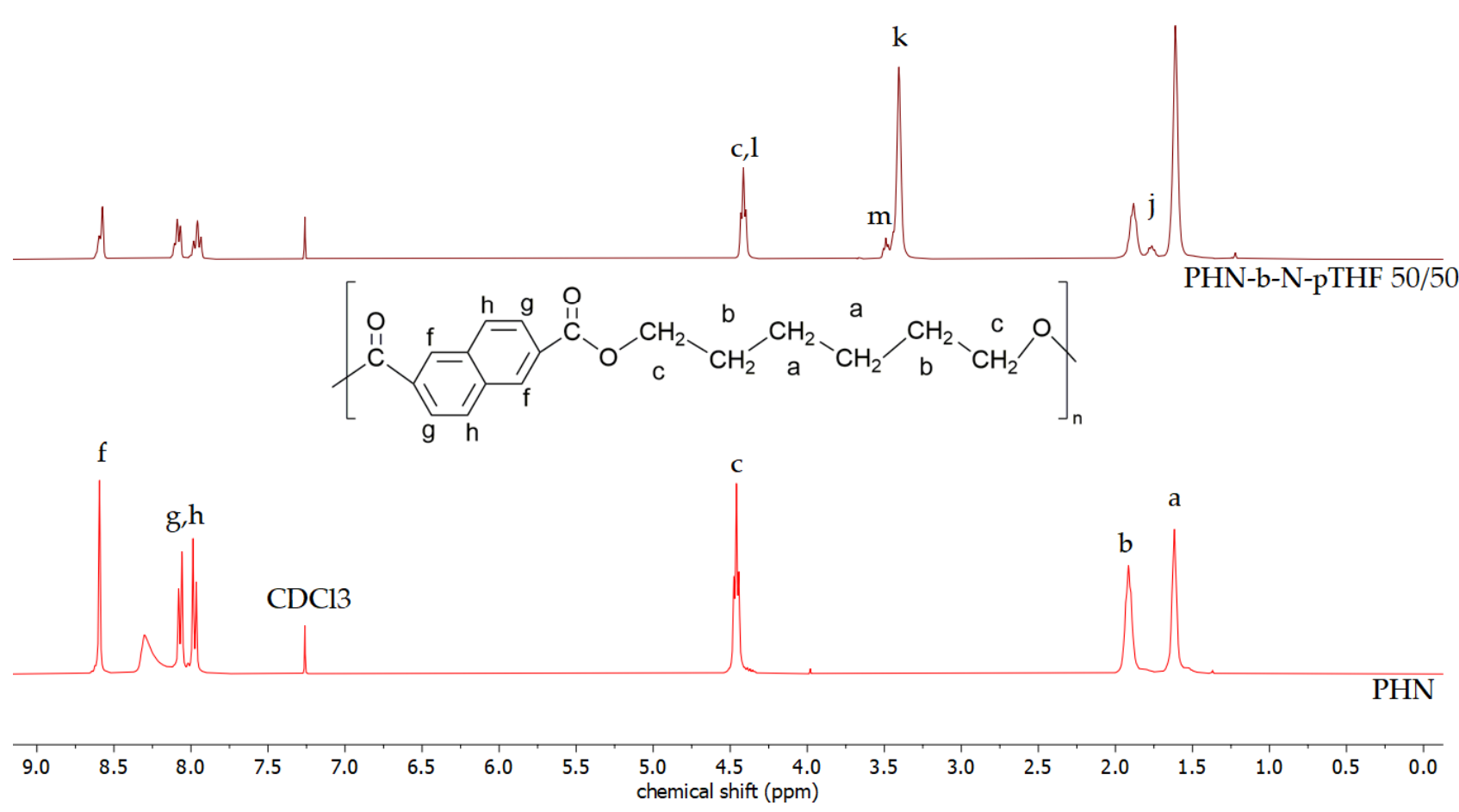

Figure 5. Structure and NMR spectra of PHN and PHN-b-N-pTHF 50/50. 
For estimation of the actual weight content of flexible segment, the Equation (1) was used:

$$
\mathrm{W}_{\mathrm{F}}(\%)=\frac{\left(\frac{\mathrm{I}_{\mathrm{F}}}{\mathrm{y}}\right) \times \mathrm{M}_{\mathrm{WF}}}{\left(\frac{\mathrm{I}_{\mathrm{F}}}{\mathrm{y}}\right) \times \mathrm{M}_{\mathrm{WF}}+\left(\frac{\mathrm{I}_{\mathrm{R}}}{\mathrm{x}}\right) \times \mathrm{M}_{\mathrm{WP}}}
$$

where $I_{R}$ is the internal signal intensities corresponding to rigid segment $I_{F}$ is the internal signal intensities corresponding to flexible segment, $\mathrm{x}$ is a number of protons assigned for an internal signal of a rigid segment (for all block copolymers $x=4$ ), $y$ is a number of protons assigned for an internal signal of the flexible segment (for all block copolymers $y=6), M_{W P}$ and $M_{W F}$ are the molecular weights of the repeating units of the rigid and flexible segment, respectively.

The difference between calculated composition and expected values is around $5 \%$. The most accurate copoly(ether-ester) is PHF-b-F-pTHF 50/50, which calculated composition differs only about $2,49 \%$ from the expected value. The difference can be caused by the introduction of additional pTHF, due to losses in the dosing of the viscous substrate and distillation of the reaction substrate under reduced pressure [22].

The FTIR analysis of polyesters and copoly(ether-ester)s was carried out to investigate their structure. In Figure 6, FTIR spectra of polyesters and copoly(ether-ester)s shown similarities that occur between $1255-1270 \mathrm{~cm}^{-1}$ and $1708-1715 \mathrm{~cm}^{-1}$. Absorption peaks in that area are caused by $\mathrm{C}(=\mathrm{O})-\mathrm{O}$ and $\mathrm{C}=\mathrm{O}$ stretching mode of ester groups, respectively $[7,21]$. There are also characteristic bands of aromatic ring moieties shown near $724-764 \mathrm{~cm}^{-1}$ (ring out-ofplane deformation), $820-875 \mathrm{~cm}^{-1}$ (ring out-of-plane deformation), 1016-1130 $\mathrm{cm}^{-1}$ (ring in-plane deformation) $[25,26]$. Moreover, for PHF and PHF-b-F-pTHF signal associated at $1222 \mathrm{~cm}^{-1}$, arising from the $=\mathrm{C}-\mathrm{O}-\mathrm{C}=$ furan ring vibration [22].

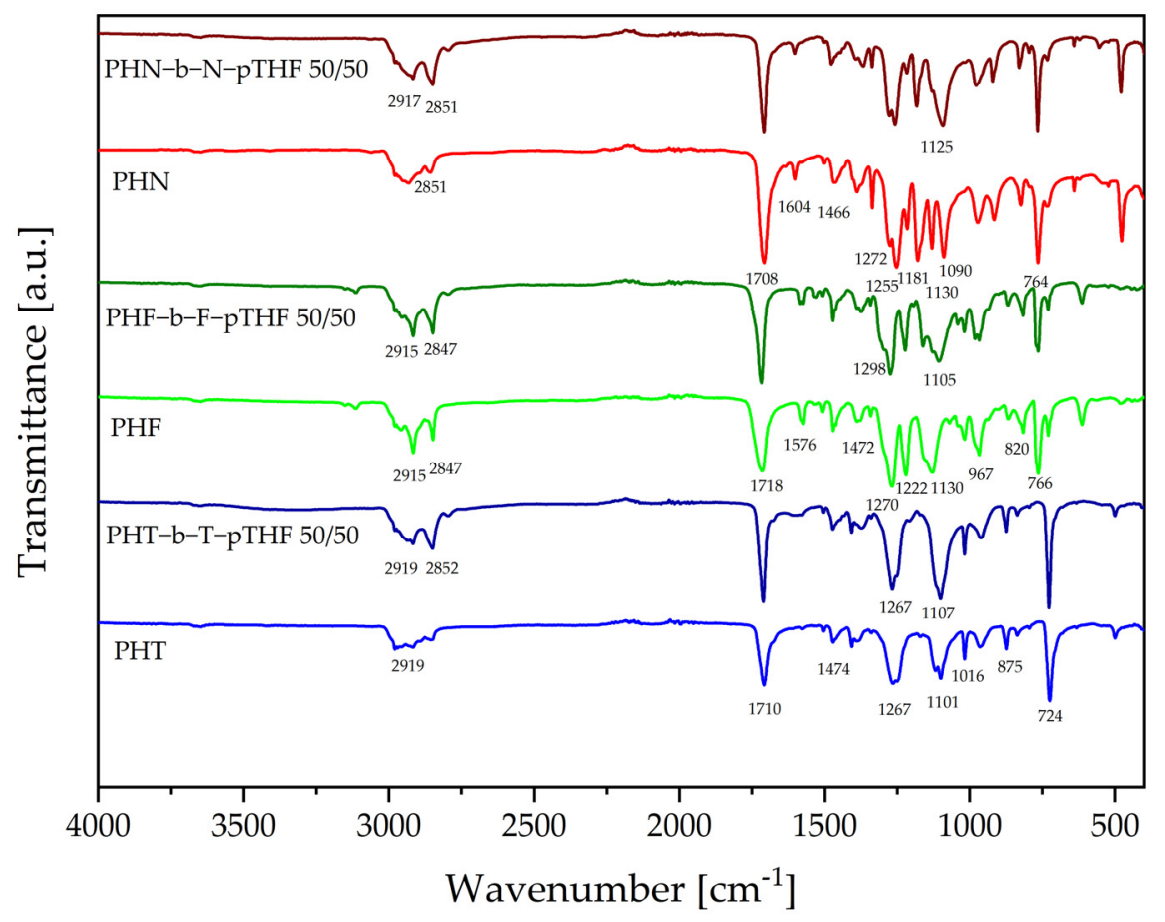

Figure 6. FTIR spectra of the synthesized materials.

The influence of soft segment on FTIR spectra is visible, especially at characteristic bands of C-O-C stretching vibration of pTHF between $1105-1125 \mathrm{~cm}^{-1}$. Consequently, after adding pTHF there is a visible increase in absorption at a wavelength of $2847-2852 \mathrm{~cm}^{-1}$ and $2915-2919 \mathrm{~cm}^{-1}$ due to $-\mathrm{C}-\mathrm{H}$ asymmetric and symmetric stretching vibrations in methylene groups [27]. Additionally, for PHF-b-F-pTHF 50/50 and PHT-b-T-pTHF 50/50 the absorption peak, associated with $\mathrm{C}=\mathrm{O}$ stretching mode of the ester group, slightly 
increased. Finally, the absorption band of -OH groups near $3450 \mathrm{~cm}^{-1}$ is very weak. Therefore, it indicates the consumption of pTHF hydroxyl groups through copolymerization, which confirms the successful modification of polyesters [22,24].

The above observations on the chemical structure and composition of polyesters and copoly(ether-esters) based on 1,6-hexanediol are in the agreement with the previously published papers [10,12,22].

In addition, the polyesters and copoly(ether-ester)s were investigated in terms of limiting viscosity number, density, and water absorption. The results are summarized in Table 3. The polyester with the highest limiting viscosity number is PHT, moreover, PHN exhibits the lowest value of limiting viscosity number $(0.626 \mathrm{dl} / \mathrm{g})$ among other polyesters. Nevertheless, all synthesized polyesters exhibited high values of intrinsic viscosity, especially if compared to PET bottle grade (IV of: $0.70-0.78$ (dl/g) [28], or to the previously synthesized PET (IV if $0.536 \mathrm{dl} / \mathrm{g}$, Mn $=19,500 \mathrm{~g} / \mathrm{mol}$ and $\mathrm{Mw}=46,900 \mathrm{~g} / \mathrm{mol}$ [29]. Whereas, the previously synthesized furan-based polyesters [30] and copoly(ether-esters) [22], following the same procedure, also exhibited relatively high values of molecular masses. Obviously, the incorporation of flexible segments into polyester caused the increase in the value of intrinsic viscosity, which is due to change in molecular chains masses and their flexibility. This is in the agreement with our previously published papers [20,22]. All synthesized polyesters exhibited similar values of hydrostatic density. Whereas, the addition of pTHF lowers values of density of copoly(ether-ester)s. Figure 7 represents the water absorption of synthesized polymers at room temperature $\left(\mathrm{CWA}\right.$ at $23^{\circ} \mathrm{C}$ ) and boiling water (HWA at $100{ }^{\circ} \mathrm{C}$ ). It is well-known that polyesters absorb water, which affects their processing properties, thus of great importance is to evaluate their affinity for water absorption [30]. Polymer materials absorb water and moisture by various mechanisms [9]. One of them is due to the diffusion of water molecules to free volume between polymer chains $[9,29,30]$. PHN has the lowest value of absorption in both, cold and hot water. PHF and PHT exhibited similar values of cold water absorption. However, PHF shows a higher absorption of hot water than PHT. In turn, copoly(ether-ester)s show significantly higher values of cold water absorption than polyesters. The lower values of HWA in the case of block copolymers might be due to the relaxation in the temperature much above the glass transition.

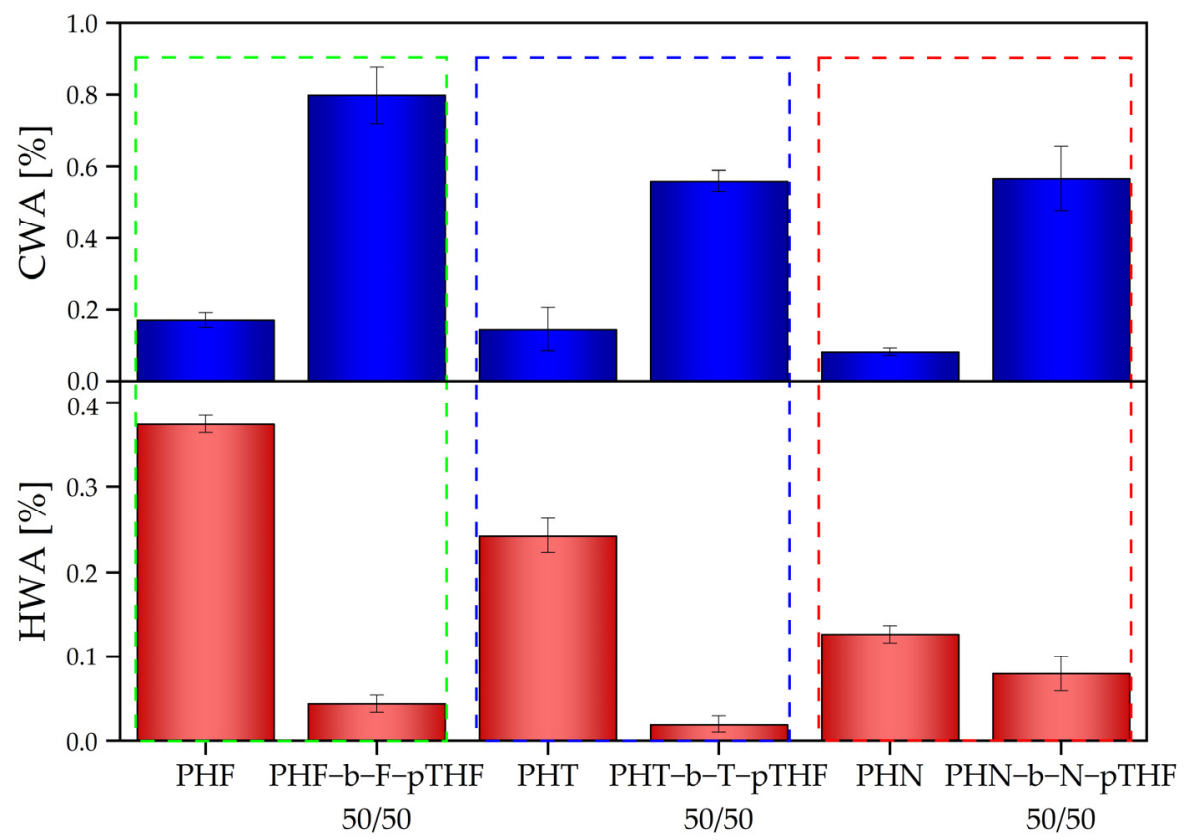

Figure 7. Water absorption in the hot and cold water of PHF, PHT, PHN, PHF-b-F-pTHF 50/50, PHT-b-T-pTHF 50/50, PHN-b-N-pTHF 50/50. 


\subsection{Structural Properties}

For an investigation of structural and thermal properties, DSC, DMTA, and XRD were used. DSC analysis is summarized in Table 4. Figure 8 represents DSC thermograms of synthesized polyesters recorded during cooling and second heating at heating/cooling rates of $10{ }^{\circ} \mathrm{C} / \mathrm{min}$ and $3{ }^{\circ} \mathrm{C} / \mathrm{min}$. Polyester with the highest value of glass transition temperature is PHN, which was due to the double aromatic ring in its chain, lowering its mobility. The glass transition temperatures of PHF and PHT are similar to one another. PHN has the highest value of melting temperature and it's the only synthesized polyester that shows cold crystallization at $194.7^{\circ} \mathrm{C}$ at a heat rate of $10^{\circ} \mathrm{C} / \mathrm{min}$. Whilst PHF has the lowest value of melting temperature. In turn, PHT has two melting temperatures, resulting from two crystal structures: $\alpha$ and $\beta$ [13]. Moreover, all investigated polyesters were found to be semi-crystalline polymers, wherein the crystallization temperatures at heat rate of $10^{\circ} \mathrm{C} / \mathrm{min}$ of $\mathrm{PHF}\left(\mathrm{T}_{\mathrm{C}}=96.8^{\circ} \mathrm{C}\right)$ and $\mathrm{PHT}\left(\mathrm{T}_{\mathrm{C}}=105.9^{\circ} \mathrm{C}\right)$ appear to be very similar, while PHN has the highest value of crystallization temperature of $169.0^{\circ} \mathrm{C}$.

Table 4. Thermal properties determined from cooling and 2nd heating thermograms for synthesized polyesters and copolymers.

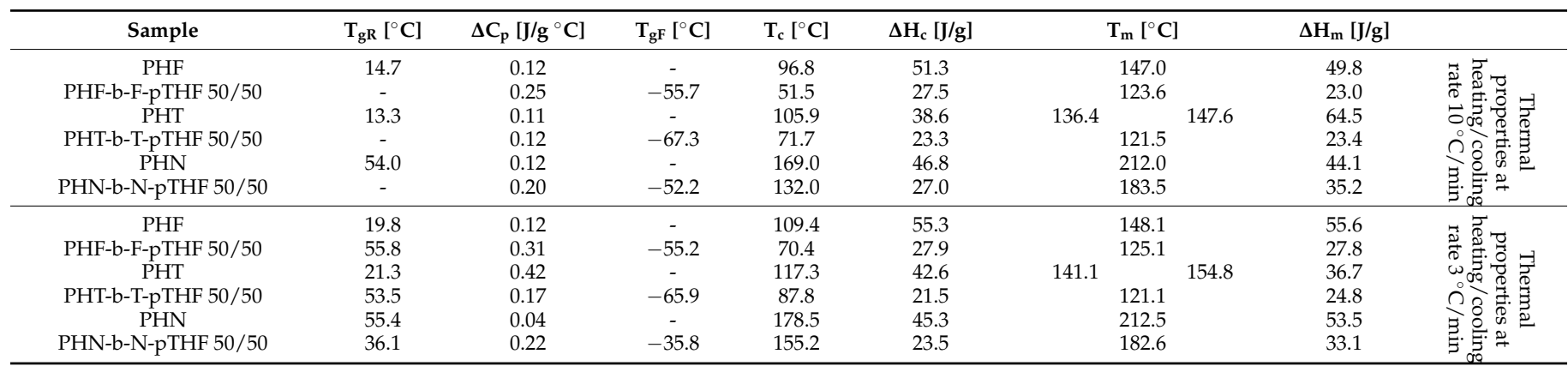

$\mathrm{T}_{\mathrm{gR}}, \mathrm{T}_{\mathrm{gF}}$ glass transition temperature of the rigid segment from second heating, and glass transition of the flexible segment from second heating, respectively; $\Delta \mathrm{C}_{\mathrm{p}}$, change of heat capacity; $\mathrm{T}_{\mathrm{c}}, \Delta \mathrm{H}_{\mathrm{c}}$, crystallization temperature and the corresponding enthalpy of crystallization; $\mathrm{T}_{\mathrm{m}}, \Delta \mathrm{H}_{\mathrm{m}}$, melting temperature and the corresponding enthalpy of melting.

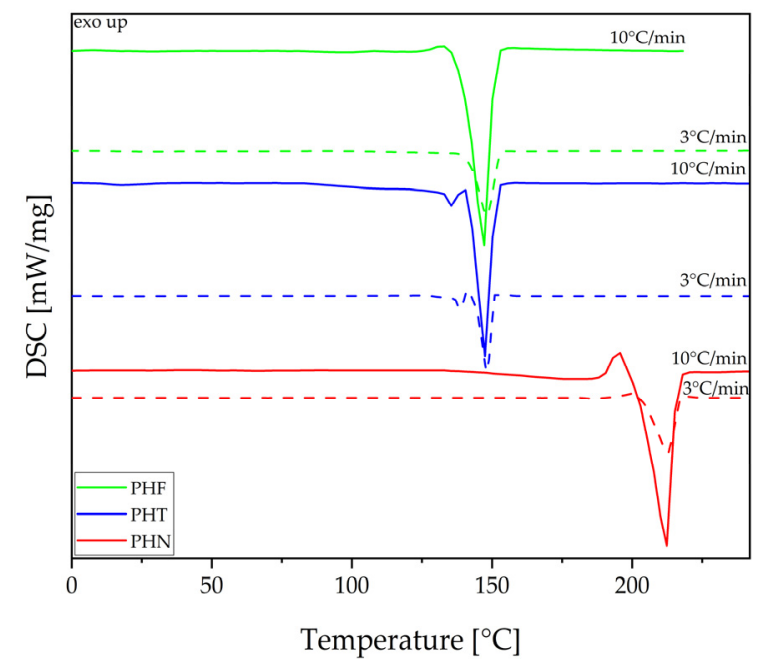

(a)

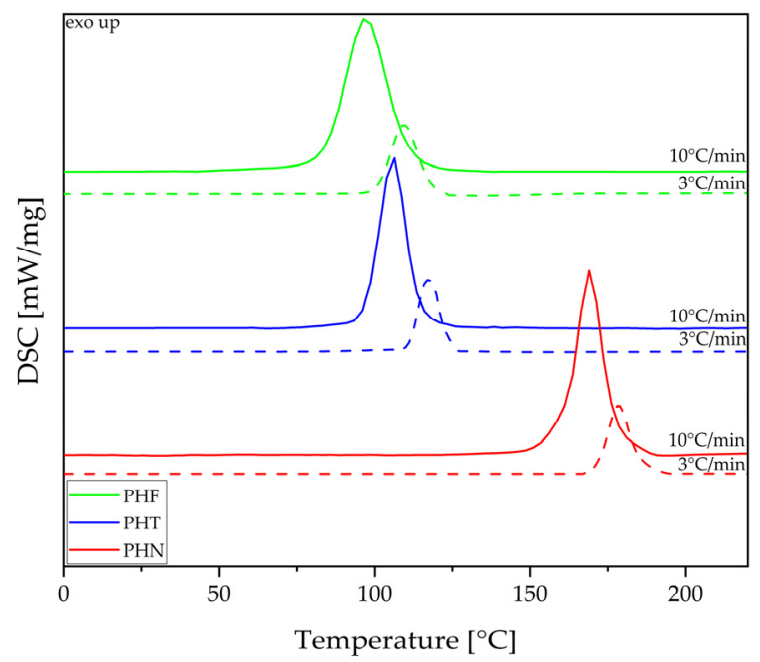

(b)

Figure 8. Differential scanning calorimetry (DSC) thermograms were recorded during the second heating (a) and cooling (b) of polyesters.

Figure 9 represents DSC thermograms of polyesters and copoly(ether-ester)s at heating/cooling rates of $10^{\circ} \mathrm{C} / \mathrm{min}$ and $3{ }^{\circ} \mathrm{C} / \mathrm{min}$. One can clearly observe the influence of flexible segment on the phase transition temperatures $\left(\mathrm{T}_{\mathrm{c}}\right.$, and $\left.\mathrm{T}_{\mathrm{m}}\right)$ that were shifted toward lower values. The phase separation between rigid and flexible segments was not visible at a 
heat rate of $10^{\circ} \mathrm{C} / \mathrm{min}$ due to crystallization of rigid segment during cooling, although one can observe two glass transitions at a heat ratio of $3{ }^{\circ} \mathrm{C} / \mathrm{min}$. For PHF-b-F-pTHF $50 / 50$ and PHT-b-T-pTHF 50/50 value of glass transition of the rigid segment increased compared to PHF and PHT, respectively. In turn, PHN-b-N-pTHF 50/50 has a lower value of glass transition of the rigid segment in comparison to the corresponding polyester.
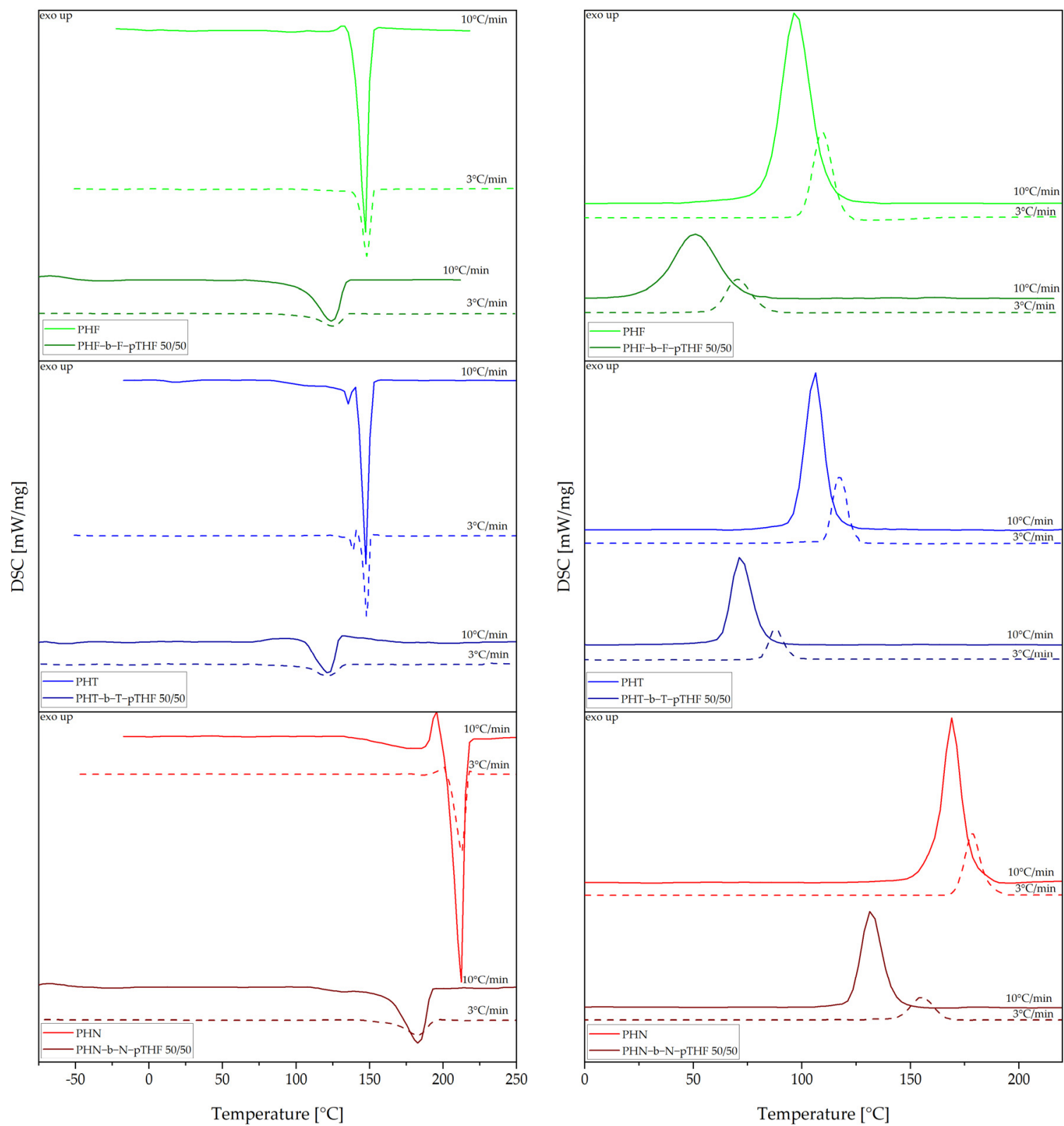

Figure 9. DSC thermograms were recorded during second heating (left panel) and cooling (right panel) for polyesters and copoly(ether-ester)s.

The crystal structure of the synthesized materials was investigated using XRD analysis. Figure 10 represents diffraction patterns of synthesized polyesters and copoly(ether-ester)s. PHF's WAXS diffractogram has three sharp signals at $2 \theta=13.67^{\circ}, 17.03^{\circ}, 24.91^{\circ}$ which are assigned respectively to planes $(110),(010),(111)[14,22]$. Similar to PHF, in WAXS diffractogram of PHN, three sharp signals at $2 \theta=16.40^{\circ}, 21.34^{\circ}, 23.64^{\circ}$ that are assigned respectively to planes (010), (111), (100) can be observed [31]. In the case of PHT, the polymorphism, suspected from DSC analysis, was confirmed. The $\alpha$ structure signals can be observed at $2 \theta=16.29^{\circ}, 19.55^{\circ}, 20.70^{\circ}, 21.44^{\circ}, 25.54^{\circ}$ [13] and signals that are coming from $\beta$ structure can be observed at $2 \theta=18.18^{\circ}, 23.64^{\circ}$ [13]. The WAXS diffractogram 
proves different crystal structures of all synthesized polyesters. In all cases of copolymers, peaks on the WAXS curves are less sharp than for polyesters due to a lower degree of crystallinity (estimated by DSC). It is especially noticeable for the $\beta$ structure of PHT-b-TpTHF 50/50 where that structure is almost not visible in the diffraction pattern.
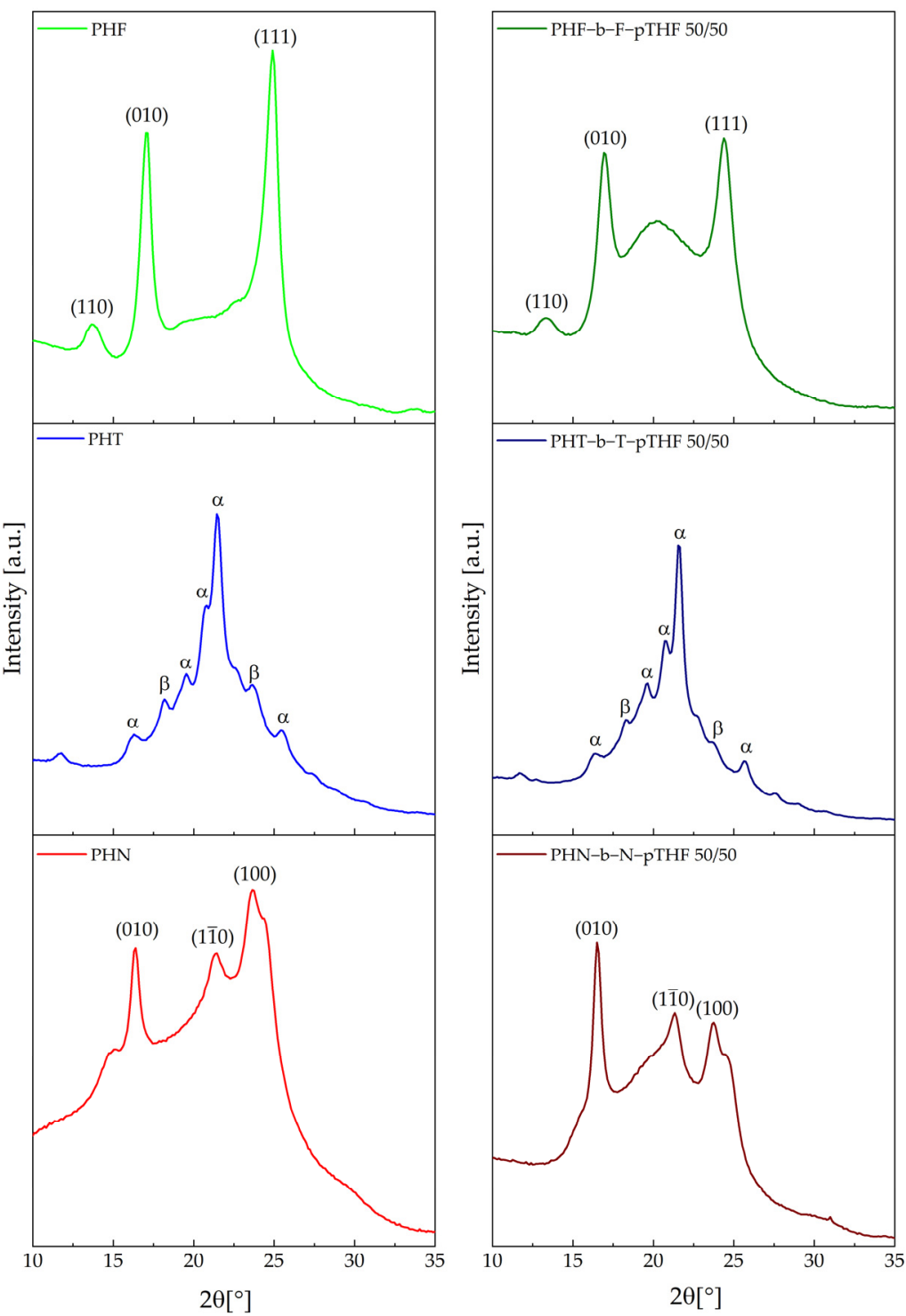

Figure 10. X-ray diffraction (XRD) curves of synthesized polyester and copolymers.

Figure 11 represents the results of DMTA where the storage modulus $\left(E^{\prime}\right)$, and $\tan \delta$ are plotted as a function of temperature at $1 \mathrm{~Hz}$. The values of $\mathrm{E}^{\prime}$ at $25^{\circ} \mathrm{C}$ and $\alpha$-relaxations are summarized in Table 5. The sample with the highest value of $\mathrm{E}^{\prime}$ at $25^{\circ} \mathrm{C}$ among polyesters is PHF (2577 MPa), while PHT has the lowest value (2105 MPa). Copolymers have significantly lower values of the storage modulus at $25^{\circ} \mathrm{C}$. In the group of copoly(ether-ester)s PHF-b-F-pTHF 50/50 exhibits the value of $\mathrm{E}^{\prime}$ at $25^{\circ} \mathrm{C}$ higher than the others $(181 \mathrm{MPa})$ when PHT-b-T-pTHF 50/50 and PHN-b-N-pTHF 50/50 differ only about 1 MPa. Copolymers show a wide plateau of elasticity that determines the possibility of using them as thermoplastic elastomers. Figure 11a represents $\tan \delta$ for polyesters, where $\alpha$-relaxation what can be recognized as $\mathrm{T}_{\mathrm{g}}$ is observed. PHN has the highest value of $\alpha_{1}\left(73^{\circ} \mathrm{C}\right)$ and PHT has the lowest value of $\alpha_{1}\left(43^{\circ} \mathrm{C}\right)$. For copoly(ether-ester)s one can clearly observe two peaks at $\tan \delta$, which are associated with $\alpha$-relaxations of rigid $\left(\alpha_{1}\right)$ and flexible $\left(\alpha_{2}\right)$ segments. Temperatures of $\alpha$-relaxations compared to values of $T_{g}$ resulting from DSC analysis at a heat rate of $3{ }^{\circ} \mathrm{C} / \mathrm{min}$ exhibit similarities in case of values $\alpha_{1}$ and $\mathrm{T}_{\mathrm{gR}}$. The 
values of $\alpha_{1}$ for PHF-b-F-pTHF 50/50 and PHT-b-T-pTHF 50/50 are higher than for PHF and PHT, respectively, when PHN-b-N-pTHF 50/50 has a lower value of $\alpha_{1}$ in comparison to PHN. Moreover, PHF-b-F-pTHF 50/50 has the highest value of $\alpha_{1}$-relaxation between copoly(ether-ester)s. In turn, PHN-b-N-pTHF 50/50 has the lowest value of $\alpha_{1}$-relaxation, although it has the highest value of $\alpha_{2}$-relaxation what can indicate partial miscibility of amorphous phases of PHN and PTHF.

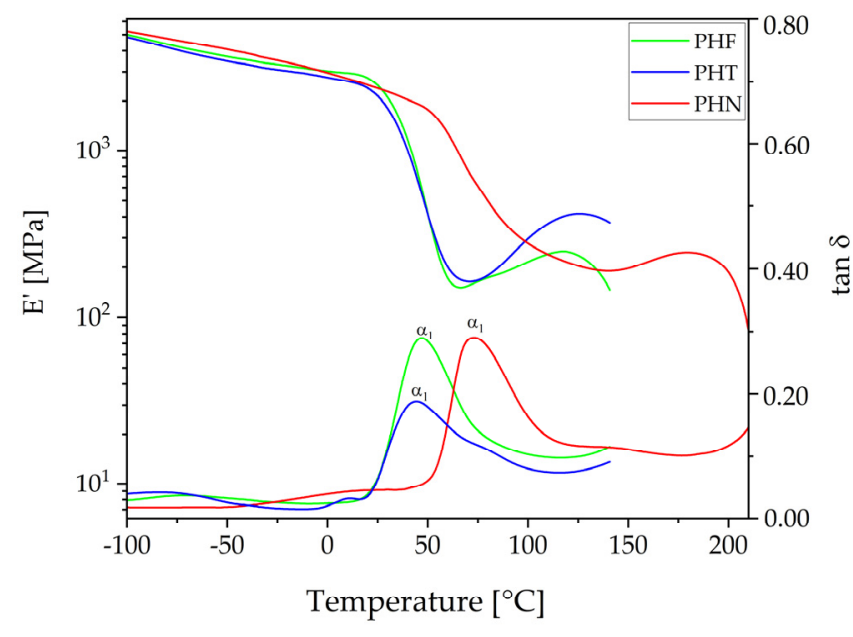

(a)

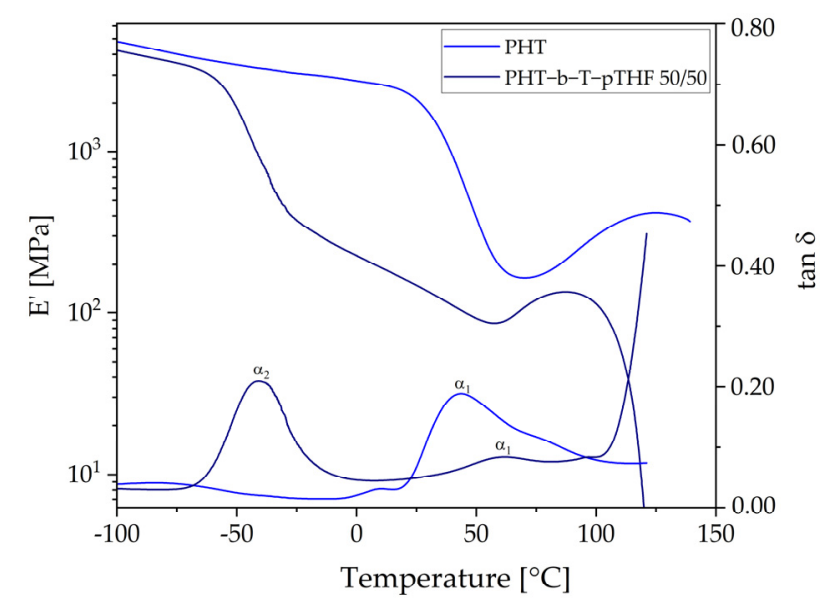

(c)

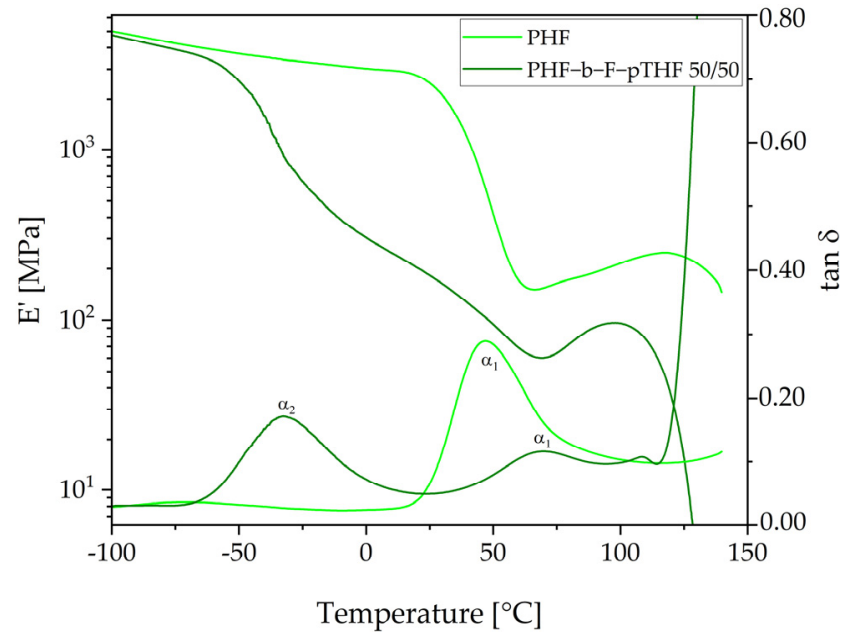

(b)

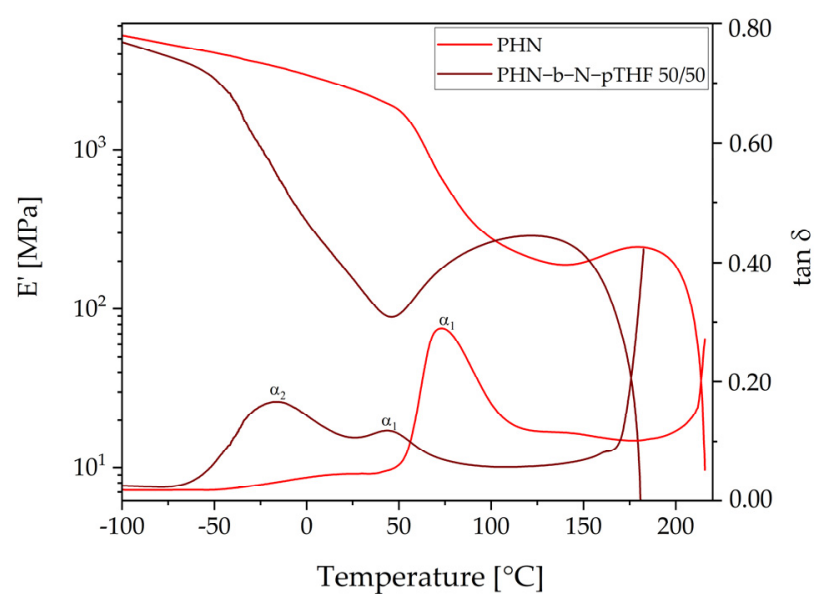

(d)

Figure 11. The storage modulus $\mathrm{E}^{\prime}(\mathbf{a}, \mathbf{c})$ and $\tan \delta(\mathbf{b}, \mathbf{d})$ as a function of temperature for polyesters and copoly(ether-ester)s.

Table 5. Properties determined from DMTA analysis for synthesized polyesters and copolymers.

\begin{tabular}{cccc}
\hline Sample & $\mathbf{E}^{\prime}$ at $25^{\circ} \mathbf{C}[\mathbf{M P a}]$ & $\mathbf{T}_{\boldsymbol{\alpha} \mathbf{1}}\left[{ }^{\circ} \mathbf{C}\right]$ & $\mathbf{T}_{\boldsymbol{\alpha} 2}\left[{ }^{\circ} \mathbf{C}\right]$ \\
\hline PHF & 2577 & 46.7 & - \\
PHF-b-F-pTHF 50/50 & 181 & 69.4 & -32.4 \\
PHT & 2105 & 43.2 & - \\
PHT-b-T-pTHF 50/50 & 151 & 61.8 & -40.4 \\
PHN & 2387 & 73.2 & - \\
PHN-b-N-pTHF 50/50 & 152 & 43.9 & -17.3 \\
\hline
\end{tabular}

$\mathrm{E}^{\prime}$-storage modulus at $25^{\circ} \mathrm{C} ; \mathrm{T}_{\alpha 1}, \mathrm{~T}_{\alpha 2}$, temperatures of $\alpha$-relaxations $\left(\alpha_{1}\right.$ and $\left.\alpha_{2}\right)$. 


\subsection{Thermal Properties}

The thermal and thermo-oxidative stability of synthesized materials was investigated due to the importance of these parameters for the future application of materials. The thermal stability of materials was performed under an inert atmosphere (argon) and thermo-oxidative stability was carried out under oxidative atmosphere (air). The characteristic temperatures for the mass losses of $5,10,50,90 \%\left(\mathrm{~T}_{5 \%}, \mathrm{~T}_{10 \%}, \mathrm{~T}_{50 \%}, \mathrm{~T}_{90 \%}\right)$ in both atmospheres and the temperatures corresponding to the maximum of mass losses ( $\mathrm{T}_{\mathrm{DTG}}$ and $\mathrm{T}_{\mathrm{DTG} 2}$ ) are summarized in Table 6 . In this study, the temperature for the mass loss of $5 \%$ is considered as the beginning of thermal degradation. Figure 12a,e represent the thermal-oxidative and thermal stability of polyesters, respectively. The values of each characteristic temperature for the mass losses and the temperatures corresponding to the maximum of mass losses in both atmospheres are almost similar. PHN has the best thermal and thermo-oxidative stability among investigated polyesters. The polyester which is most sensitive for degradation is PHF. The difference between values of $\mathrm{T}_{5 \%}$, and $\mathrm{T}_{\mathrm{DTG} 1}$ in both atmospheres for PHF and PHN is almost about $20^{\circ} \mathrm{C}$.

Table 6. TGA data: temperatures of 5\%, 10\%, 50\%, 90\% mass loss, the temperatures corresponding to Table 1 and $\mathrm{T}_{\mathrm{DTG} 2}$ ) in an oxidizing and inert atmosphere.

\begin{tabular}{|c|c|c|c|c|c|c|}
\hline Sample & $\mathrm{T}_{5 \%}\left({ }^{\circ} \mathrm{C}\right)$ & $\mathrm{T}_{10 \%}\left({ }^{\circ} \mathrm{C}\right)$ & $\mathrm{T}_{50 \%}\left({ }^{\circ} \mathrm{C}\right)$ & $\mathrm{T}_{90 \%}\left({ }^{\circ} \mathrm{C}\right)$ & $\mathrm{T}_{\text {DTG1 }}\left({ }^{\circ} \mathrm{C}\right)$ & $\mathrm{T}_{\mathrm{DTG} 2}\left({ }^{\circ} \mathrm{C}\right)$ \\
\hline \multicolumn{7}{|c|}{ Measurement in an Oxidizing Atmosphere } \\
\hline PHF & 362 & 369 & 386 & 409 & 386 & 470 \\
\hline PHF-b-F-pTHF 50/50 & 328 & 341 & 378 & 434 & 386 & 494 \\
\hline PHT & 374 & 380 & 401 & 481 & 400 & 500 \\
\hline PHT-b-T-pTHF 50/50 & 348 & 363 & 398 & 501 & 398 & 503 \\
\hline PHN & 380 & 388 & 409 & 532 & 406 & 529 \\
\hline PHN-b-N-pTHF 50/50 & 354 & 368 & 405 & 527 & 405 & 521 \\
\hline \multicolumn{7}{|c|}{ Measurement in an inert atmosphere } \\
\hline PHF & 362 & 369 & 385 & 405 & 385 & - \\
\hline PHF-b-F-pTHF 50/50 & 334 & 348 & 385 & 409 & 391 & - \\
\hline PHT & 370 & 380 & 402 & 471 & 403 & - \\
\hline PHT-b-T-pTHF 50/50 & 366 & 377 & 404 & 432 & 405 & - \\
\hline PHN & 382 & 390 & 412 & - & 409 & - \\
\hline PHN-b-N-pTHF 50/50 & 378 & 387 & 411 & 616 & 411 & - \\
\hline
\end{tabular}

$\mathrm{T}_{5 \%}, \mathrm{~T}_{10 \%}, \mathrm{~T}_{50 \%}$ and $\mathrm{T}_{90 \%}$-temperatures corresponding to $5 \%, 10 \%, 50 \%$ and $90 \%$ of mass loss, $\mathrm{T}_{\mathrm{DTG} 1}$ and $\mathrm{T}_{\mathrm{DTG} 2}$-the temperatures corresponding to the maximum of mass losses. 


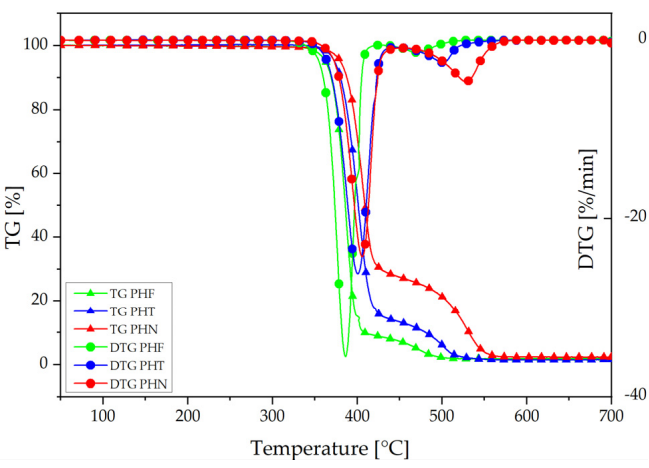

(a)

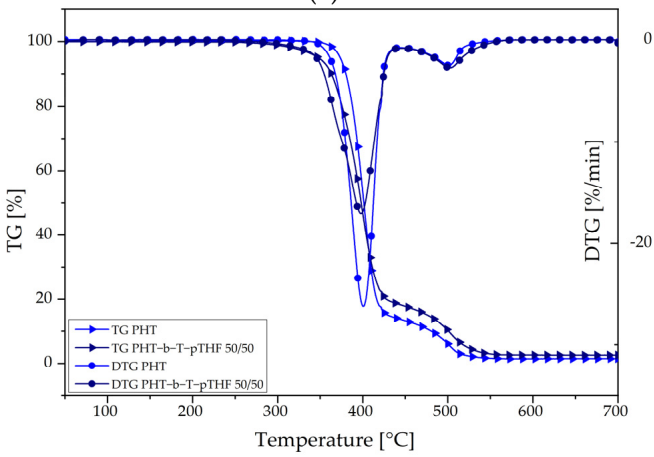

(c)

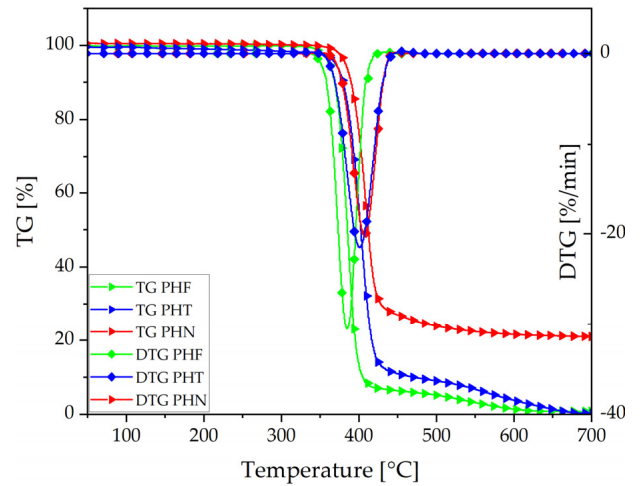

(e)

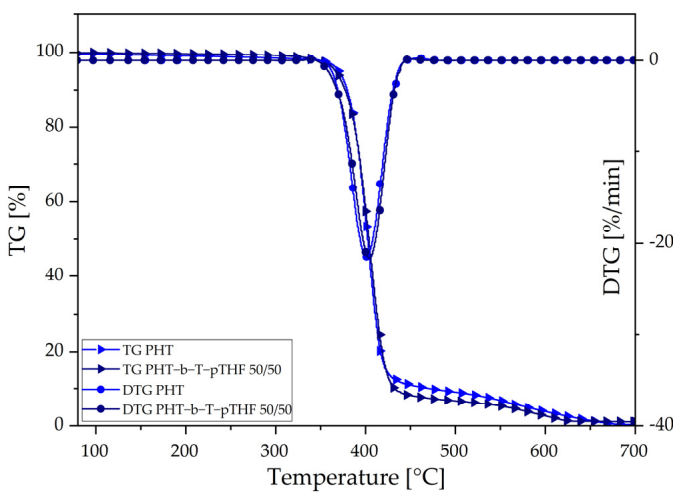

(g)

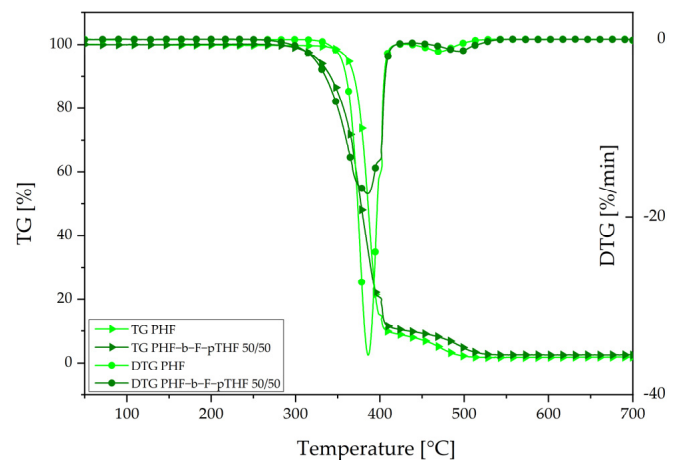

(b)

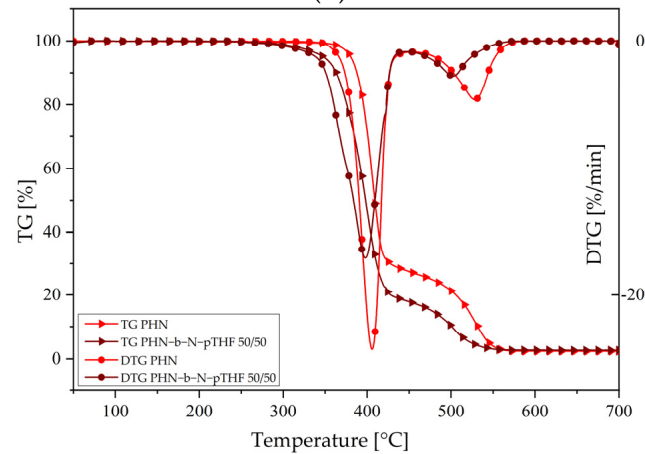

(d)

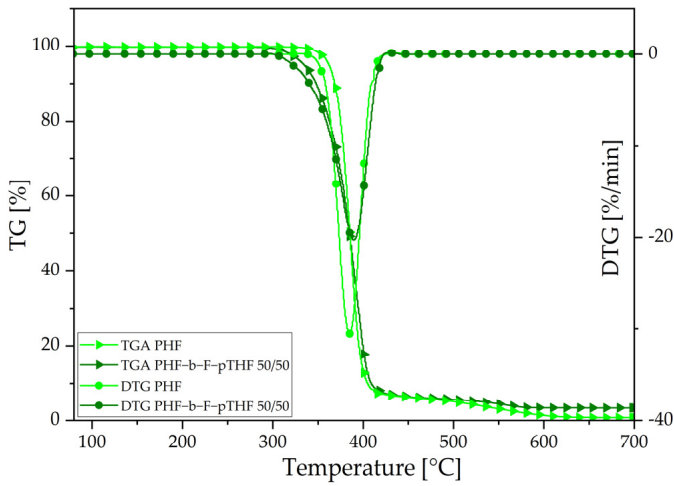

(f)

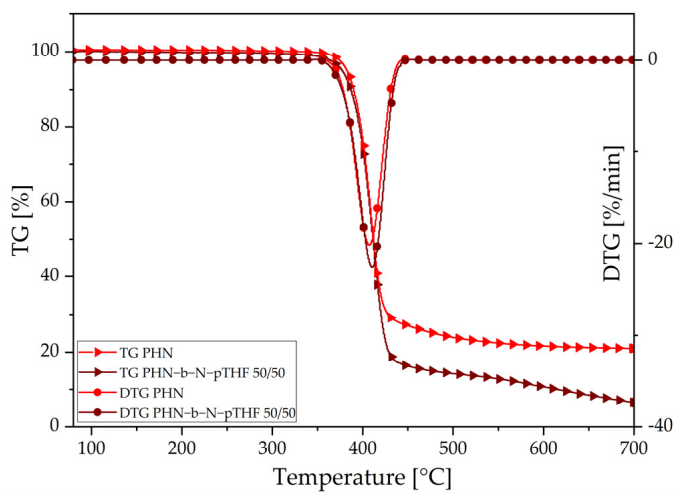

(h)

Figure 12. TG and DTG curves for synthesized materials measured in an oxidizing atmosphere (a-d) and in an inert atmosphere (argon) $(\mathbf{e}-\mathbf{h})$ at the heating rate of $10^{\circ} \mathrm{C} / \mathrm{min}$.

Figure $12 \mathrm{~b}-\mathrm{d}, \mathrm{f}-\mathrm{h}$ represents thermo-oxidative and thermal stability of polyesters and copoly(ether-ester)s, respectively. The influence of soft segment in copoly(ether-ester)s is significant. Especially, it is noticeable in the decrease in the value of $T_{5 \%}$ of mass loss of 
copoly(ether-ester)s in comparison to corresponding polyesters. The first derivative of the mass loss (DTG) curve in Figure 12b-d shows two-step decomposition under an oxidative atmosphere. The first step appears at $386-405^{\circ} \mathrm{C}$ and its attributed to the decomposition of flexible and rigid segments. The second step appears at $470-529{ }^{\circ} \mathrm{C}$, and it results from the decomposition of residue. The values of $\mathrm{T}_{\mathrm{DTG} 1}$ for polyesters and copoly(ether-ester)s do not show great differences, only about $2{ }^{\circ} \mathrm{C}$. Although, there is a significant difference in the value of $\mathrm{T}_{\mathrm{DTG} 2}$ between them. For PHF-b-F-pTHF $50 / 50$ value of $\mathrm{T}_{\mathrm{DTG} 2}$ is $24^{\circ} \mathrm{C}$ higher than for PHF. A similar effect was observed by Szymczyk et al. [32] for poly(trimethylene terephthalate)-block-poly(ethylene oxide) (PTT-b-PEO) copolymers. The value of $\mathrm{T}_{\mathrm{DTG}}$ for PHT and PHT-b-T-pTHF 50/50 is almost similar; furthermore, PHN has a higher value of $\mathrm{T}_{\text {DTG2 }}$ than PHN-b-N-pTHF 50/50.

\subsection{Mechanical Properties}

Figure 13 represents the stress-strain curves of the synthesized materials. The values of Young modulus $(E)$, tensile strength at yield $\left(\sigma_{\mathrm{y}}\right)$, elongation at yield $\left(\varepsilon_{\mathrm{y}}\right)$, tensile strength at break $\left(\sigma_{\mathrm{b}}\right)$, and elongation at yield $\left(\varepsilon_{\mathrm{y}}\right)$ are summarized in Table 7 . All polyesters show a strain hardening effect due to the orientation of macromolecular chains and crystallization during stretching. PHN has the highest value of Young modulus among other polyesters, by about $1 \mathrm{TPa}$. Moreover, the values of tensile strength at yield and tensile strength at break of PHN are higher than for PHF and PHT. However, the polyester that characterizes significantly better elongation is PHT, which elongation at break differs from others around $100 \%$. The addition of soft segment results in the disappearance of yield point, significant increase value of elongation at break, and decrease in value of tensile strength at break. The disappearance of yield point is due to the initiation of highly elastic deformations at low deformation. These characteristics are typical for elastomeric materials. The most promising copoly(ether-ester) is PHN-b-N-pTHF 50/50. This material has the highest value of tensile strength at break and its value of elongation at break classify between PHF-b-F-pTHF 50/50 and PHT-b-T-pTHF 50/50. Due to the addition of pTHF ability to crystallization decreased and it caused a decrease in a strain hardening effect. The hardness of polyesters and copoly(ether-ester)s are summarized in Table 7. The polyester with the highest value of Shore D hardness in PHN. The hardness value of PHF and PHT slightly differs. However, the addition of soft segment results in a decrease in hardness in copoly(ether-ester)s in comparison to polyesters.

Table 7. Tensile properties of synthesized polyesters and copoly(ether-ester)s.

\begin{tabular}{ccccccc}
\hline Sample & $\left.\mathbf{H ~}_{\mathbf{S}} \mathbf{S h}^{\circ} \mathbf{D}\right]$ & $\mathbf{E}[\mathbf{M P a}]$ & $\boldsymbol{\sigma}_{\mathbf{y}}[\mathbf{M P a}]$ & $\varepsilon_{\mathbf{y}}[\mathbf{\%}]$ & $\boldsymbol{\sigma}_{\mathbf{b}}[\mathbf{M P a}]$ & $\boldsymbol{\varepsilon}_{\mathbf{b}}[\%]$ \\
\hline PHF & $65 \pm 1$ & $395.8 \pm 41.7$ & $23.3 \pm 0.4$ & $8.5 \pm 0,4$ & $44.8 \pm 1.8$ & $319.4 \pm 17.3$ \\
PHF-b-F-pTHF 50/50 & $40 \pm 1$ & $56.6 \pm 7.6$ & - & - & $30.6 \pm 1.1$ & $564.9 \pm 30.0$ \\
PHT & $62 \pm 1$ & $372.3 \pm 33.2$ & $19.6 \pm 0.4$ & $13.9 \pm 0.6$ & $38.4 \pm 3.1$ & $421.4 \pm 21.0$ \\
PHT-b-T-pTHF 50/50 & $34 \pm 1$ & $57.6 \pm 8.9$ & - & - & $15.8 \pm 0.2$ & $671.3 \pm 15.6$ \\
PHN & $75 \pm 1$ & $1347.3 \pm 20.6$ & $41.4 \pm 6.0$ & $4.4 \pm 1.5$ & $46.0 \pm 0.5$ & $340.2 \pm 3.1$ \\
PHN-b-N-pTHF 50/50 & $41 \pm 1$ & $76.8 \pm 3.1$ & - & - & $31.2 \pm 0.8$ & $606.9 \pm 33.7$ \\
\hline
\end{tabular}

E-Young's modulus (calculated from strain $0.05 \%$ to $0.25 \%$ ); $\sigma_{y}$-tensile strength at yield; $\varepsilon_{y}$-elongation at yield; $\sigma_{b}$-tensile strength at break; $\varepsilon_{b}$ - elongation at break, H-hardness. 


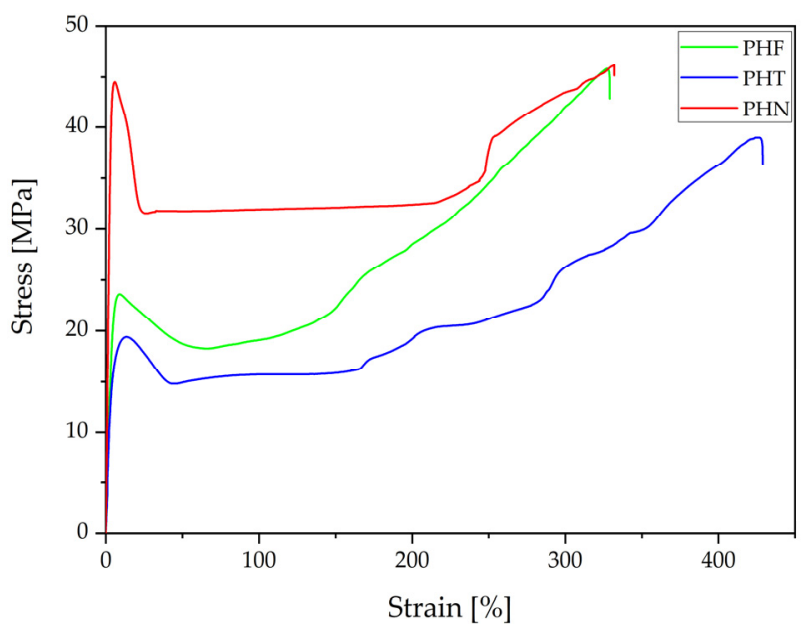

(a)

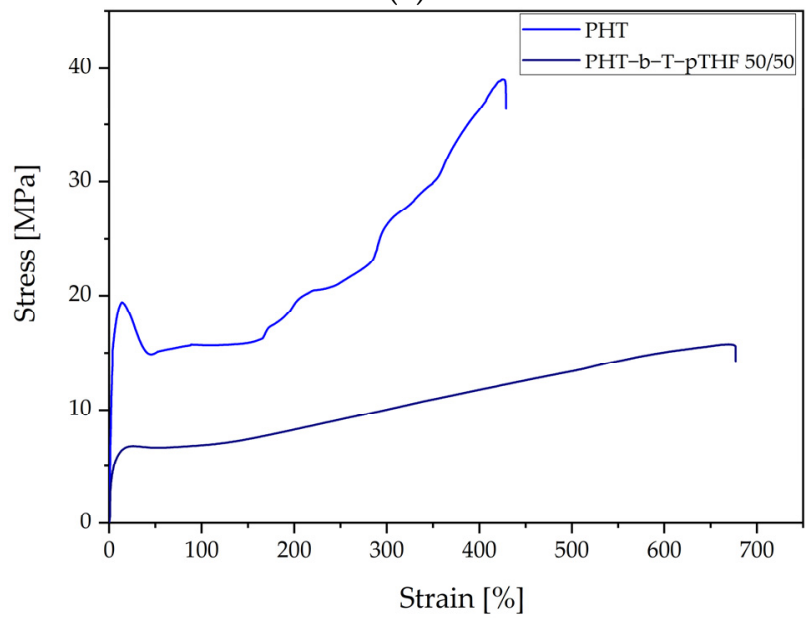

(c)

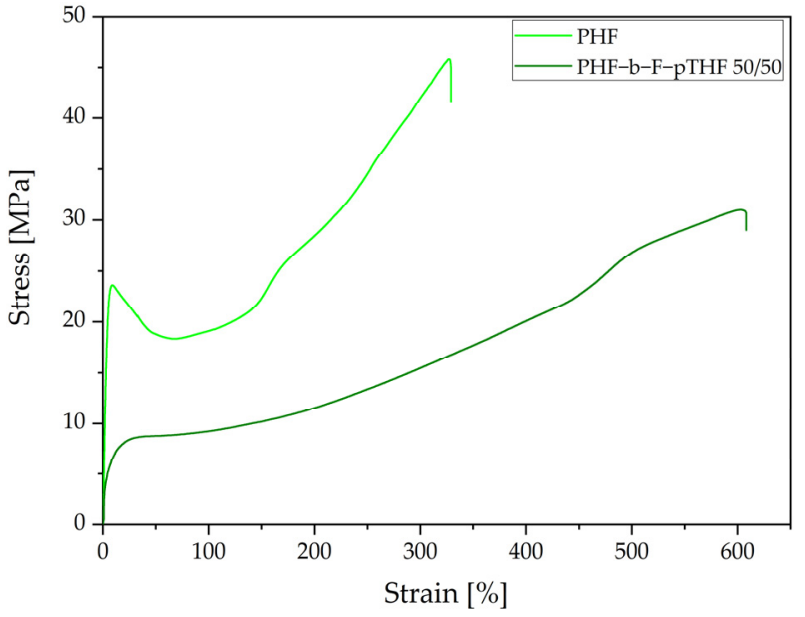

(b)

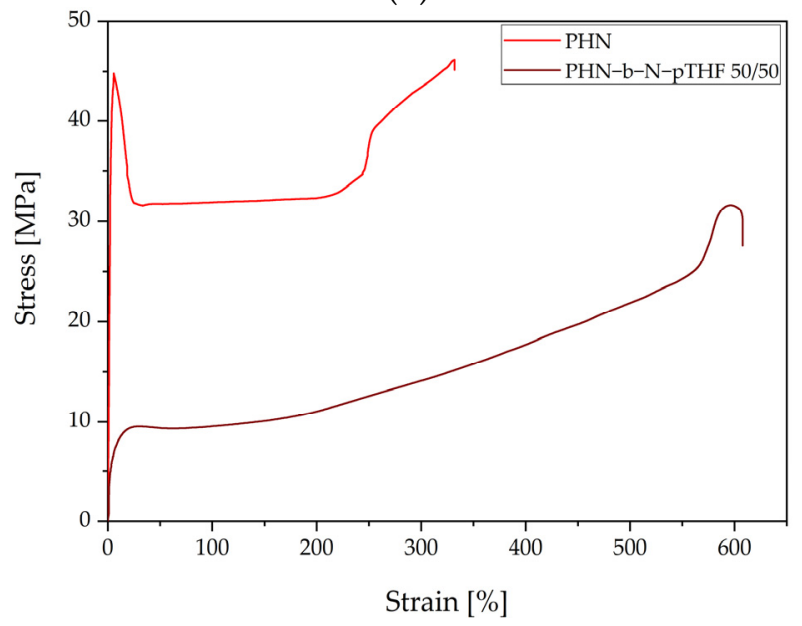

(d)

Figure 13. Representative stress-strain curves of static tensile test for synthesized materials (a) polyesters, (b) PHF and PHF-b-F-pTHF 50/50, (c) PHT and PHT-b-T-pTHF 50/50, (d) PHN and PHN-b-N-pTHF 50/50.

\section{Conclusions}

The synthesis of PHF, PHT, PHN, and copoly(ether-ester)s by two-step melt polycondensation was carried out successfully. Synthesized materials were investigated and compared in terms of chemical structure, mechanical, thermal, utilitarian properties. The chemical structure of materials was analyzed by FTIR spectroscopy and ${ }^{1} \mathrm{H}$ quantitative nuclear magnetic resonance (NMR) and it confirmed that real composition is similar to feed one. Using DSC, DMTA, TGA thermal properties and phase structure of synthesized materials were studied. The crystal structure was investigated by XRD analysis. The static tensile performance was carried out for polyesters and copoly(ether-ester)s. Moreover, intrinsic viscosity number, density, and water absorption were studied. All investigated polyesters are semicrystalline. The obtained copolymers are characterized by high values of deformation. Additionally, synthesized copolymers can be processed by injection molding. These characteristics prove the attainment of TPE. Among synthesized materials, the most prominent are PHN and PHN-b-N-pTHF 50/50 due to their properties. They characterize by the most rigid macromolecular chain since their value of glass transition temperature and thermal stability are significantly higher than others. Moreover, their values of hardness, Young modulus, and tensile strength at break are higher as well. However, dimethyl naphthalate is more expensive than traditional TPA so complete replacement of it is not profitable. PHF and PHT show similarities in phase transition temperatures and hardness. PHT has slightly better thermal and thermal-oxidative properties than PHF, 
although PHF is characterized by a higher value of Young modulus and tensile strength at break than PHT. In the future, PHF could be prioritized over PHT due to being a bio-based material and a decrease in the price of FDCA. Moreover, if comparing the synthesized copoly(ether-ester)s, based on PHF and PHN, with commercially available thermoplastic elastomers with similar values of hardness (Shore hardness ca. $40 \mathrm{ShD}$ )—for instance, Hytrel $^{\circledR} 4056$ [33,34] — the obtained materials are found to have higher values of elongation and tensile stress at break. A slightly lower value of $\sigma_{b}$ was observed for PHT- b-T-pTHF $50 / 50$, when keeping the excellent value of $\varepsilon_{\mathrm{b}}$, comparable to the values typically observed for commercially available TPE. The above-mentioned statement clearly demonstrates the application potential of the synthesized TPEs based on all employed diesters.

Author Contributions: Writing—original draft preparation, K.W.; writing—review and editing, investigation and formal analysis, I.I.; formal analysis, Z.R.; investigation, A.Z.; writing-review and editing, supervision, funding acquisition, S.P. All authors have read and agreed to the published version of the manuscript.

Funding: The studies were financed by the National Science Centre within project SONATA no 2018/31/D/ST8/00792.

Institutional Review Board Statement: Not applicable.

Informed Consent Statement: Not applicable.

Data Availability Statement: The data presented in this study are available on request from the corresponding author. After publication the data will be kept in the open repositories by means of Mendeley Data and RepOD.

Conflicts of Interest: The authors declare no conflict of interest.

\section{References}

1. BASF. Now Offers Bio-Based PolyTHF. Available online: https://www.basf.com/global/en/media/news-releases/2015/03/p15-163.html (accessed on 2 April 2021).

2. Christ, E.M.; Herzberger, J.; Montigny, M.; Tremel, W.; Frey, H. Poly(THF-Co-Cyano Ethylene Oxide): Cyano Ethylene Oxide (CEO) Copolymerization with THF Leading to Multifunctional and Water-Soluble PolyTHF Polyelectrolytes. Macromolecules 2016, 49, 3681-3695. [CrossRef]

3. Rennovia Enters Piloting Stage of Its Bio-Based 1,6-Hexanediol Process. Available online: https://www.bioplasticsmagazine. com/en/news/meldungen/20170329-Rennovia-takes-step-towards-commercialization-of-biobased-platform.php (accessed on 2 April 2021).

4. Papageorgiou, G.Z.; Papageorgiou, D.G.; Terzopoulou, Z.; Bikiaris, D.N. Production of Bio-Based 2,5-Furan Dicarboxylate Polyesters: Recent Progress and Critical Aspects in Their Synthesis and Thermal Properties. Eur. Polym. J. 2016, 83, $202-229$. [CrossRef]

5. Zhao, D.; Delbecq, F.; Len, C. One-Pot FDCA Diester Synthesis from Mucic Acid and Their Solvent-Free Regioselective Polytransesterification for Production of Glycerol-Based Furanic Polyesters. Molecules 2019, 24, 1030. [CrossRef]

6. Sousa, A.F.; Coelho, J.F.J.; Silvestre, A.J.D. Renewable-Based Poly((Ether)Ester)s from 2,5-Furandicarboxylic Acid. Polymer 2016, 98, 129-135. [CrossRef]

7. Papageorgiou, G.Z.; Tsanaktsis, V.; Papageorgiou, D.G.; Chrissafis, K.; Exarhopoulos, S.; Bikiaris, D.N. Furan-Based Polyesters from Renewable Resources: Crystallization and Thermal Degradation Behavior of Poly(Hexamethylene 2,5-Furan-Dicarboxylate). Eur. Polym. J. 2015, 67, 383-396. [CrossRef]

8. Sousa, A.F.; Fonseca, A.C.; Matos, M. Biobased Polyesters and Other Polymers from 2,5-Furandicarboxylic Acid: A Tribute to Furan Excellency. Polym. Chem. 2015, 6, 5961-5983. [CrossRef]

9. Paszkiewicz, S.; Irska, I.; Piesowicz, E. Environmentally Friendly Polymer Blends Based on Post-Consumer Glycol-Modified Poly(Ethylene Terephthalate) (PET-G) Foils and Poly(Ethylene 2,5-Furanoate) (PEF): Preparation and Characterization. Materials 2020, 13, 2673. [CrossRef] [PubMed]

10. Martı, A.; Ilarduya, D.; Herrera, V.; Mun, S. Poly (Hexamethylene Terephthalate- Co -Caprolactone) Copolyesters Obtained by Ring-Opening Polymerization. Macromolecules 2008, 41, 4136-4146.

11. González-Vidal, N.; de Ilarduya, A.M.; Muñoz-Guerra, S.; Castell, P.; Martínez, M.T. Synthesis and Properties of Poly(Hexamethylene Terephthalate)/Multiwall Carbon Nanotubes Nanocomposites. Compos. Sci. Technol. 2010, 70, 789-796. [CrossRef]

12. Heum, J.; Gyu, Y.; Cheol, S.; Ghyl Min, B.; Ho, W. Cocrystallization Behavior of Poly (Hexamethylene Terephthalate-CoHexamethylene 2,6-Naphthalate) Random Copolymers. Polymer 2002, 43, 5263-5270. 
13. Yen, K.C.; Woo, E.M.; Chen, Y.F. Amorphous-Phase Miscibility and Crystal Phases in Blends of Polymorphic Poly(Hexamethylene Terephthalate) with Monomorphic Poly(Pentamethylene Terephthalate). Polym. J. 2007, 39, 935-944. [CrossRef]

14. Jiang, M.; Liu, Q.; Zhang, Q.; Ye, C.; Zhou, G. A Series of Furan-Aromatic Polyesters Synthesized via Direct Esterification Method Based on Renewable Resources. J. Polym. Sci. Part A Polym. Chem. 2012, 50, 1026-1036. [CrossRef]

15. Papageorgiou, G.Z.; Papageorgiou, D.G.; Tsanaktsis, V.; Bikiaris, D.N. Synthesis of the Bio-Based Polyester Poly(Propylene 2,5-Furan Dicarboxylate). Comparison of Thermal Behavior and Solid State Structure with Its Terephthalate and Naphthalate Homologues. Polymer 2015, 62, 28-38. [CrossRef]

16. Jeong, Y.G.; Jo, W.H.; Lee, S.C. Synthesis and Crystallization Behavior of Poly(m-Methylene 2,6-Naphthalate-Co-1,4Cyclohexylenedimethylene 2,6-Naphthalate) Copolymers. Macromolecules 2003, 36, 4051-4059. [CrossRef]

17. Gyu, Y.; Ho, W.; Cheol, S. Crystal Structure of Poly (Pentamethylene 2,6-Naphthalate). Polymer 2002, 43, 7315-7323.

18. Baltá Calleja, F.J.; Roslaniec, Z. Block Copolymers, 1st ed.; CRC Press: Boca Raton, FL, USA, 2000.

19. Fakirov, S. Handbook of Condensation Thermoplastic Elastomers; Wiley: Hoboken, NJ, USA, 2006.

20. Szymczyk, A.; Senderek, E.; Nastalczyk, J.; Roslaniec, Z. New Multiblock Poly(Ether-Ester)s Based on Poly(Trimethylene Terephthalate) as Rigid Segments. Eur. Polym. J. 2008, 44, 436-443. [CrossRef]

21. Soccio, M.; Gazzano, M.; Lotti, N.; Finelli, L.; Munari, A. Synthesis and Characterization of Novel Random Copolymers Based on PBN: Influence of Thiodiethylene Naphthalate Co-Units on Its Polymorphic Behaviour. Polymer 2010, 51, 192-200. [CrossRef]

22. Paszkiewicz, S.; Irska, I.; Zubkiewicz, A.; Szymczyk, A.; Piesowicz, E.; Rozwadowski, Z.; Goracy, K. Biobased Thermoplastic Elastomers: Structure-Property Relationship of Poly(Hexamethylene 2,5-Furanodicarboxylate)-Block-Poly(Tetrahydrofuran) Copolymers Prepared by Melt Polycondensation. Polymers 2021, 13, 397. [CrossRef]

23. Chen, J.; Chen, D.; Huang, W.; Yang, X.; Li, X.; Tu, Y.; Zhu, X. A One Pot Facile Synthesis of Poly (Butylene Terephthalate)Block-Poly (Tetramethylene Oxide) Alternative Multiblock Copolymers via PROP Method. Polymer 2016, 107, 29-36. [CrossRef]

24. Aleksandrovic, V.; Poleti, D.; Djonlagic, J. Poly(Ether-Ester)s Modified with Different Amounts of Fumaric Moieties. Polymer 2002, 43, 3199-3208. [CrossRef]

25. Vasanthan, N.; Salem, D.R. Structural and Conformational Characterization of Poly(Ethylene 2,6-Naphthalate) by Infrared Spectroscopy. Macromolecules 1999, 32, 6319-6325. [CrossRef]

26. Lee, D.H.; Park, K.H.; Kim, Y.H.; Lee, H.S. Surface Chain Orientation during Crystallization Induction Period of Poly(Pentamethylene 2,6-Naphthalate) Studied with Polarized FTIR-ATR. Macromolecules 2007, 40, 6277-6282. [CrossRef]

27. Chi, D.; Liu, F.; Na, H.; Chen, J.; Hao, C.; Zhu, J. Poly(Neopentyl Glycol 2,5-Furandicarboxylate): A Promising Hard Segment for the Development of Bio-Based Thermoplastic Poly(Ether-Ester) Elastomer with High Performance. ACS Sustain. Chem. Eng. 2018, 6, 9893-9902. [CrossRef]

28. Polymers I Intrinsic Viscosity Measurements for Quality Control of PET. Available online: https://www.anton-paar.com/corpen/services-support/document-finder/application-reports / polymers-intrinsic-viscosity-measurements-for-quality-controlof-pet/ (accessed on 20 May 2021).

29. Paszkiewicz, S.; Szymczyk, A.; Špitalský, Z.; Soccio, M.; Mosnáček, J.; Ezquerra, T.A.; Rosłaniec, Z. Electrical Conductivity of Poly(Ethylene Terephthalate)/Expanded Graphite Nanocomposites Prepared by in Situ Polymerization. J. Polym. Sci. Part B Polym. Phys. 2012, 50, 1645-1652. [CrossRef]

30. Zubkiewicz, A.; Paszkiewicz, S.; Szymczyk, A. The Effect of Annealing on Tensile Properties of Injection Molded Biopolyesters Based on 2,5-Furandicarboxylic Acid. Polym. Eng. Sci. 2021, 61, 1536-1545. [CrossRef]

31. Jeong, Y.G.; Jo, W.H.; Lee, S.C. Crystal Structure of Poly (Hexamethylene 2, 6-Naphthalate). Polym. J. 2001, 33, 913-919. [CrossRef]

32. Szymczyk, A. Structure and Properties of New Polyester Elastomers Composed of Poly(Trimethylene Terephthalate) and Poly(Ethylene Oxide). Eur. Polym. J. 2009, 45, 2653-2664. [CrossRef]

33. Hytrel ${ }^{\circledR} 4056$ Thermoplastic Polyester Elastomer. Available online: https://dupont.materialdatacenter.com/products/datasheet/ SI/Hytrel\%C2\%AE\%204056 (accessed on 9 August 2021).

34. DuPont ${ }^{\mathrm{TM}}$ Hytrel $^{\circledR}$ Thermoplastic Polyester Elastomer Product Reference Guide. Available online: https://www.dupont.com/ content/dam/dupont/amer/us/en/transportation-industrial/public/documents/en/Hytrel\%20Product $\% 20$ Reference $\% 20$ Guide.pdf (accessed on 9 August 2021). 